\title{
PHYSICAL MODELING EXPERIMENTS TO STUDY PERIODIC ACTIVATION OF FAULTS IN SEISMIC ZONES
}

\author{
S. A. Bornyakov1, 2, I. A. Panteleev³, A. V. Cheremnykh1', A. A. Karimova1, 2 \\ ${ }^{1}$ Institute of the Earth's Crust, Siberian Branch of RAS, Irkutsk, Russia \\ 2 Irkutsk State University, Irkutsk, Russia \\ ${ }^{3}$ Institute of Continuous Media Mechanics, Ural Branch of RAS, Perm, Russia
}

\begin{abstract}
Our study aimed to find a mechanism that controls preparation and subsequent full seismic activation of large faults that may act as sources of strong earthquakes. A large fault was physically modeled to investigate the dynamics of its deformation. The experiments were conducted on elastoviscoplastic and elastic models of the lithosphere. A digital camera was used to capture images in the course of the modeling experiments. The digital image correlation method (DIC) detected the moments of impulse activation and displacements along the entire fault or its major segment. Between the activation moments, the fault structure consists of segments, including active ones. Activation is directional and involves a few large segments of the fault, then numerous small ruptures, and the latter are gradually degenerating. The long-term deformation dynamics of the fault is represented by a regular sequence of its full activations. In most cases, each moment of activation correlates with a minimum dip angle of the repeatability curve $(\beta)$ and a maximum value of information entropy $\left(\mathrm{S}_{\mathrm{i}}\right)$. We analysed in detail the deformation dynamics of the fault and in its wings between two full activation that occurred in a regular pattern, including the phases of regression and progression of the deformation process. The analysis revealed two similar scenarios in the evolution of the active segments and plastic micro slip faults within the active segments. In some intervals of time, deformation takes place considerably differently on the segments and the plastic micro slip faults. Such differences suggest that in the studies attempting to statistically predict and assess a large and potentially seismically hazardous fault zone, this zone should be considered spatially subdivided into a central narrow subzone (including the main fault plane) and two wide subzones framing the fault wings. According to our physical modeling results, the central subzone can be up to $10 \mathrm{~km}$ wide, and the total width of all the subzones can amount to $100 \mathrm{~km}$ or more. This study contributes to the development of the concepts of geodynamics of large faults in the seismic zones of the lithosphere and investigates one of the possible mechanisms preparing strong earthquakes in the seismic zones.
\end{abstract}

Key words: physical modeling; fault; segmentation; seismogenic activation

\section{RESEARCH ARTICLE}

Received: May 23, 2018

Revised: July 21, 2018

Handling Editor: K.Zh. Seminsky

Accepted: August 2, 2018

For citation: Bornyakov S.A., Panteleev I.A., Cheremnykh A.V., Karimova A.A., 2018. Physical modeling experiments to study periodic activation of faults in seismic zones. Geodynamics \& Tectonophysics 9 (3), 653-670. doi:10.5800/GT-2018-9-3-0366.

Для цитирования: Борняков С.А., Пантелеев И.А., Черемных А.В., Каримова А.А. Экспериментальное исследование периодической активизации разлома в сейсмической зоне // Геодинамика и тектонофизика. 2018. Т. 9. № 3. C. 653-670. doi:10.5800/GT-2018-9-30366. 


\title{
ЭКСПЕРИМЕНТАЛЬНОЕ ИССЛЕДОВАНИЕ ПЕРИОДИЧЕСКОЙ АКТИВИЗАЦИИ РАЗЛОМА В СЕЙСМИЧЕСКОЙ ЗОНЕ
}

\author{
С. А. Борняков ${ }^{1,2}$, И. А. Пантелеев ${ }^{3}$, А. В. Черемных ${ }^{1}$, А. А. Каримова1, 2 \\ ${ }^{1}$ Институт земной коры СО РАН, Иркутск, Россия \\ ${ }^{2}$ Иркутский государственный университет, Иркутск, Россия \\ ${ }^{3}$ Институт механики сплошных сред УрО РАН, Пермь, Россия
}

\begin{abstract}
Аннотация: С целью поиска механизма, управляющего подготовкой и последующей полной сейсмической активизацией крупных разломов как источников сильных землетрясений, выполнено физическое моделирование деформационной динамики крупного разлома в упруговязкопластичной и упругой моделях литосферы. Моделируемый процесс фотографировался цифровой камерой с последующей компьютерной обработкой методом корреляции цифровых изображений (digital image correlation, DIC). Результаты обработки показали, что в моменты импульсной активизации происходит реализация смещений по всему разрыву или на его большей части. Между такими активизациями разрыв имеет сегментную структуру с направленной эволюцией активных сегментов - от нескольких крупных сегментов к многочисленным мелким с постепенным вырождением последних. Долговременная деформационная динамика разрыва представлена закономерной последовательностью его полных активизаций. Установлено, что моментам таких активизаций в большинстве случаев соответствуют минимальные значения угла наклона графика повторяемости ( $\beta$ ) и максимальные значения информационной энтропии $\left(\mathrm{S}_{\mathrm{i}}\right)$. Детальный анализ динамики деформаций на разрыве и в его крыльях между двумя полными активизациями показал, что они происходят закономерно в рамках регрессивной и прогрессивной фаз деформационного процесса с проявлением двух одноименных сценариев эволюции активных сегментов и пластических микросдвигов в их пределах. Установлено, что деформационная активность сегментов и пластических микросдвигов на отдельных временных интервалах существенно отличается. Из этого следует, что при статистических прогнозных оценках зоны крупных сейсмоопасных разломов следует пространственно подразделять на центральную узкую подзону с магистральной плоскостью сместителя и две обрамляющие ее внешние широкие подзоны в его крыльях. С учетом результатов физического моделирования ширина центральной подзоны может составлять до 10 км, а суммарная ширина всех подзон - до 100 км и более. В целом, результаты экспериментов способствуют развитию представлений о геодинамике крупных разломов в сейсмических зонах литосферы и показывают один из возможных механизмов подготовки в них сильных землетрясений.
\end{abstract}

Ключевые слова: физическое моделирование; разлом; сегментация; сейсмогенная активизация

\section{1. ВВЕДЕНИЕ}

Настоящая статья посвящена памяти профессора С.И. Шермана, основателя и многолетнего лидера сибирской тектонофизической научной школы. Главный научный интерес С.И. Шермана сформировался в начале творческого пути под влиянием идей двух классиков отечественной тектонофизики - В.Н. Даниловича и М.В. Гзовского, определивших объект и методологию его исследований на всю последующую профессиональную жизнь. Таким объектом для него стали разломы, и он всегда оставался верен этому своему научному кредо, последовательно развивая и совершенствуя преимущественно на количественной основе тектонофизику разломообразования и сопутствующего ему сейсмического процесса. Логическим венцом его многолетних исследований стали тектонофизическая концепция и модель сейсмической зоны [Sherman, 2014]. Эта концепция рассматривает сей- смическую зону как самостоятельную объемную структуру литосферы разломной природы, внутреннее строение которой составляют закономерные совокупности разноранговых активных разломов и вычленяемых ими блоков. Разломы, в соответствии с их масштабным рангом, контролируют пространственное положение очагов землетрясений разных магнитуд. Показано, что их селективная сейсмическая активизация происходит вследствие триггерного воздействия мигрирующих по сейсмической зоне медленных деформационных волн. Механизм такого воздействия подтверждается результатами физического моделирования [Bornyakov et al., 2016a, 2016b]. При этом отмечено, что триггерному воздействию преимущественно поддаются небольшие разломы или отдельные участки крупных разломов, находящиеся в критическом метастабильном состоянии и генерирующие землетрясения малых и средних классов. Открытым остается вопрос механизма подго- 
товки и последующей полной сейсмической активизации крупных разломов, ответственных за сильные тектонические землетрясения.

По устоявшемуся представлению периодическая активизация уже существующих в сейсмической зоне разломов преимущественно реализуется в соответствии с моделью прерывистого скольжения "stick-slip" [Brace, Byerlee, 1966]. Известны многочисленные примеры экспериментального воспроизведения этой модели в лабораторных условиях. Как правило, в таких экспериментах использовалась нагружаемая с фиксированной скоростью модельная конструкция из двух блоков, изготовленных из горных пород или близких к ним по механическим свойствам искусственных материалов. Основной акцент при этом ставился на инструментальную регистрацию различных физических явлений, предшествующих реализации импульсной подвижки, рассматриваемой как модельный аналог землетрясения в природе. С точки зрения теории подобия [Gzovsky, 1975; Sherman, 1984], обсуждаемые эксперименты при использованных граничных условиях воспроизводили процессы подготовки и реализации слабых сейсмических событий, обусловленных сейсмогенной активизацией небольших разломов в верхней, упругой, части литосферы. При подготовке же сильного землетрясения в деформацию вовлекаются большие объемы литосферы, проявляющие наряду с упругими и ряд неупругих реологических свойств, что необходимо учитывать при моделировании процессов активизации крупных сейсмоактивных разломов.

С целью дальнейшего развития предложенной в работе [Sherman, 2014] тектонофизической модели сейсмической зоны авторами выполнено физическое моделирование процесса периодической активизации крупного разлома в упруговязкопластичной и упругой моделях литосферы.

\section{2. МЕТОДЫ МОДЕЛИРОВАНИЯ И ОБРАБОТКИ ДАННЫХ}

В работе использованы два вида физического моделирования: моделирование деформационной динамики крупного разлома в упруговязкопла- стичной модели и моделирование полей упругих напряжений в области динамического влияния крупного разлома в упругой, оптически активной модели.

\section{1. МЕТОДИКА МОДЕЛИРОВАНИЯ ДЕФОРМАЦИОННОЙ ДИНАМИКИ КРУПНОГО РАЗЛОМА В УПРУГОВЯЗКОПЛАСТИЧНОЙ МОДЕЛИ}

Условия подобия. Определение граничных условий эксперимента по воспроизведению процесса периодической активизации крупного разлома проводилось с использованием критерия подобия [Gzovsky, 1975; Sherman, 1984]:

$$
\mathrm{C}_{\eta}=\mathrm{C}_{\rho} \cdot \mathrm{C}_{\mathrm{g}} \cdot \mathrm{C}_{\mathrm{L}} \cdot \mathrm{C}_{\mathrm{T}}
$$

где $\eta$ - вязкость, Па.с; $\rho$ - плотность, кг $/ \mathrm{M}^{3} ; \mathrm{g}-$ ускорение свободного падения, M/c ${ }^{2}$; - линейные размеры, м; Т - время, с; $\mathrm{C}_{\eta}$ - коэффициент подобия вязкости; $\mathrm{C}_{\rho}$ - коэффициент подобия плотности; $\mathrm{Cg}$ - коэффициент подобия ускорения свободного падения; $\mathrm{C}_{\mathrm{L}}$ - коэффициент подобия линейных размеров; $\mathrm{C}_{\mathrm{T}}$ - коэффициент подобия времени.

В нашем случае коэффициенты подобия составляли: для вязкости $-\mathrm{C}_{\eta} \sim 10^{14}$; для плотности $-\mathrm{C}_{\rho} \sim 1.3$; для ускорения свободного падения $\mathrm{C}_{\mathrm{g}}=1$; для линейных размеров - $\mathrm{C}_{\mathrm{l}} \sim 0^{5}$ и для времени $\mathrm{C}_{\mathrm{t}} \sim 5 \cdot 10^{9}$ при использованных параметрах для зоны разлома и ее аналога в модели (табл. 1). При таких значениях коэффициентов подобия 1 мм в модели соответствует 0.1 км в ее природном аналоге, а 1 с эксперимента эквивалентна 16-17 годам природного процесса.

Модельный материал. Выбор модельного материала осуществлялся с учетом упруговязкопластичного поведения литосферы при длительно действующих на нее нагрузках [Sherman, 1977]. В рамках временной длительности эксперимента при используемых скоростях нагружения моделей сходные с литосферой реологические свойства имеют водные пасты глин. Нами использована водная паста глины, правомерность использования которой в качестве модельного материала обоснована специально проведенным исследованием [Seminsky, 1986].

\section{Т а б л и ц а 1. Значения основных параметров для зоны разлома и ее аналога в модели}

$\mathrm{T}$ a b l e 1. Main parameters of a fault zone in nature and model

\begin{tabular}{llllll}
\hline \multirow{2}{*}{ Тип зоны разлома } & \multicolumn{5}{l}{ Основные параметры зоны разлома и их значения } \\
\cline { 2 - 6 } & $\rho$ & $\mathrm{g}$ & $\mathrm{L}$ & $\mathrm{T}$ & $\eta$ \\
\hline Натурный & $2.0 \mathrm{\kappa г} / \mathrm{m}^{3}$ & $9.8 \mathrm{м} / \mathrm{c}$ & $4.5 \cdot 10^{4} \mathrm{M}$ & $5 \cdot 10^{9} \mathrm{c}$ & $\sim 10^{18}$ Па·с \\
Модельный & $1.5 \mathrm{\kappa г} / \mathrm{m}^{3}$ & $9.8 \mathrm{~m} / \mathrm{c}$ & $4.5 \cdot 10^{-1} \mathrm{M}$ & $\sim 10 \mathrm{c}$ & $\sim 10^{4}$ Па·с \\
\hline
\end{tabular}


(a)

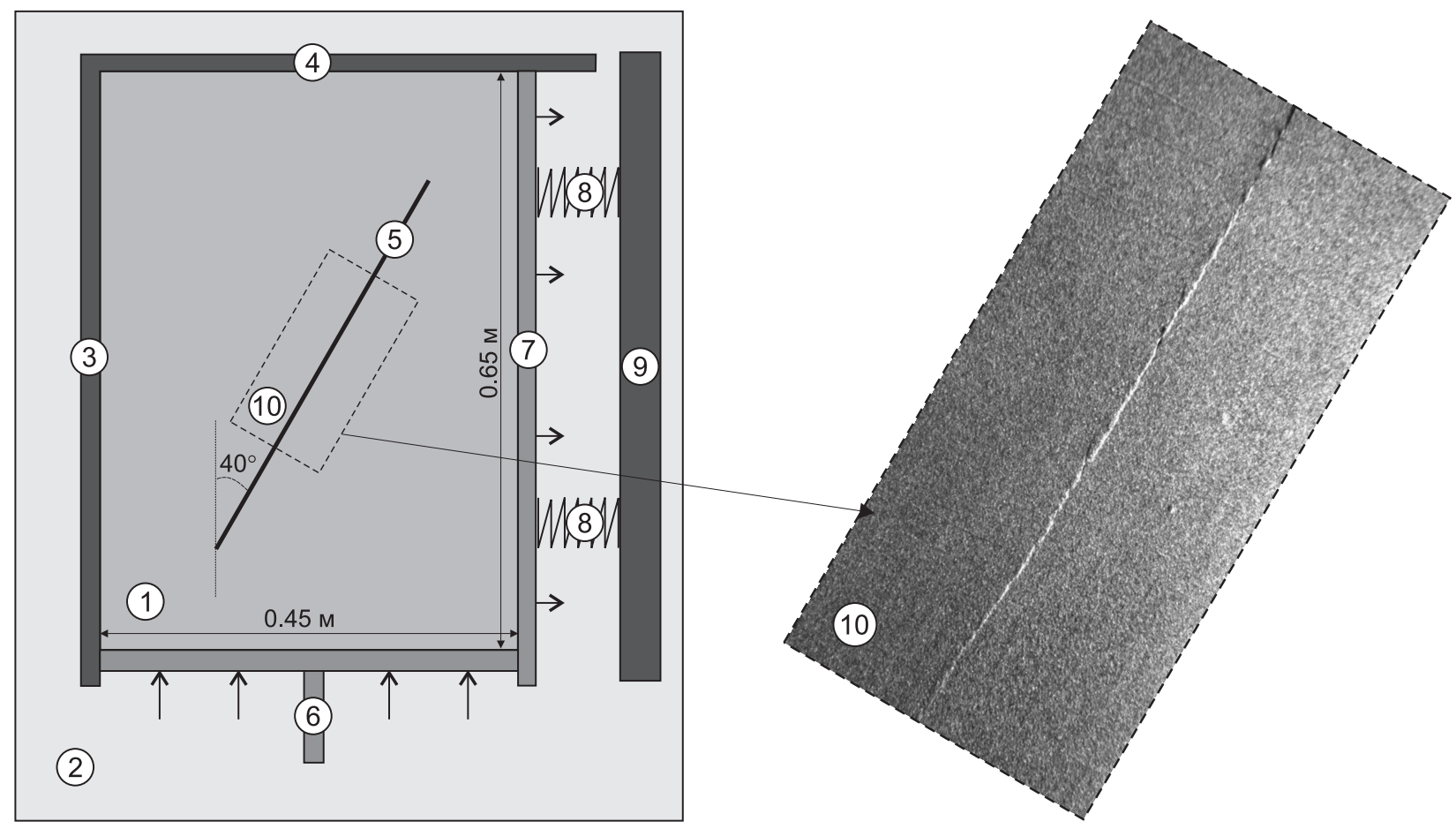

| Рис. 1. Схема эксперимента (a) и фото модели с разрывом (б). Пояснения цифр в тексте.

Fig. 1. Schematic diagram of physical modeling experiments $(a)$ and fault model image (б). Numbers - see explanations in the text.

Экспериментальное оборудование, техника подготовки и проведения экспериментов. Эксперименты выполнены на установке «Разлом» [Bornyakov et al., 2014] с использованием дополнительно изготовленных конструкций. На рис. $1, a$, представлена схема эксперимента. Модель из эквивалентного материала (1), длиной 0.65 м, шириной 0.45 м и толщиной 0.1 м, располагалась на листе оргстекла (2), смазанного вазелиновым маслом. С торцов модель имела неподвижные боковой (3) и фронтальный (4) упоры. При подготовке модели в нее закладывалась вертикально прямоугольная пластина из оргстекла (5) длиной 0.45 м, высотой 0.1 м и толщиной 0.001 м под углом $40^{\circ}$ к направлению движения активного штампа (6). Пластина извлекалась до начала эксперимента, оставляя после себя искусственно созданную неоднородность, имитирующую существующий в литосфере региональный разлом. Модель подвергалась сжатию штампом (6), перемещающимся с постоянной скоростью движения $10^{-5}$ м/с в направлении, указанном стрелками. Модель была ограничена подвижным штампом (7), поджатым пружинами (8), соединенными с неподвижным упором (9). При деформации модели штамп (7) имел возможность перемещаться в сторону упора (9).

До эксперимента на модель тонким слоем насыпался мелкий песок. Отдельные песчинки выступа- ли в роли многочисленных реперов, используемых впоследствии для расчета деформаций. Развивающийся в модели процесс фотографировался в пределах рабочей площадки (10) цифровой фотокамерой "Basler" acA1920-40gm с частотой 1 fps (1 кадр в секунду). Обработка полученных изображений проводилась методом корреляции цифровых изображений.

\section{2. МЕТОДИКА МОДЕЛИРОВАНИЯ ПОЛЕЙ НАПРЯЖЕНИЙ В СИСТЕМЕ РАЗРЫВОВ В УПРУГОЙ ОПТИЧЕСКИ АКТИВНОЙ МОДЕЛИ}

Условия подобия. Подобие при моделировании на оптически-активных эквивалентных материалах рассмотрено в работах М.В. Гзовского, Д.Н. Осокиной, С.И. Шермана и других [Osokina, 1963; Gzovsky, 1975; Sherman, 1984; Osokina, Bondarenko, 1989; и др.]. При моделировании быстро протекающих процессов, таких как сейсмические события, во внимание принимается только упругое поведение геологической среды. Соответственно, моделирование проводится с использованием упругих эквивалентных материалов, удовлетворяющих условию подобия:

$$
\mathrm{C}_{\mathrm{E}}=\mathrm{C}_{\rho} \mathrm{C}_{\mathrm{g}} \mathrm{C}_{\mathrm{L}} \text {, }
$$


где C - коэффициенты подобия: E - упругих свойств материалов, $\rho$ - плотностей, L - размеров, $\mathrm{g}$ - ускорений свободного падения.

Коэффициенты подобия вычисляются по формулам:

$$
\begin{aligned}
& \mathrm{C}_{\mathrm{E}}=\mathrm{E}_{\text {модели }} / \mathrm{E}_{\text {горных пород; }} \\
& \mathrm{C}_{\rho}=\rho_{\text {модели }} / \rho_{\text {горных пород; }} \\
& \mathrm{C}_{\mathrm{g}}=\mathrm{g}_{\text {при моделировании }} / \mathrm{g}_{\mathrm{B} \text { природе; }} \\
& \mathrm{C}_{\mathrm{L}}=\mathrm{L}_{\mathrm{B} \text { модели }} / \mathrm{L}_{\mathrm{B} \text { природе. }}
\end{aligned}
$$

Мгновенный модуль упругости горных пород изменяется от $10^{4}$ до $3 \cdot 10^{5}$ МПа [Osokina, Bondarenko, 1989], а модуль упругости студня с концентрацией желатина 25 \% составляет 0.05 МПа [Osokina, 1963]. Таким образом, $\mathrm{C}_{\mathrm{E}}$ изменяется в диапазоне от $10^{-6}$ до 10-7. Коэффициент подобия плотностей $\mathrm{C}_{\rho}=0.4-0.5$, так как плотность желатинового студня в 2.0-2.5 раза меньше, чем у горных пород. В связи с тем, что эксперименты проводятся при естественном поле силы тяжести Земли, $\mathrm{C}_{\mathrm{g}}=1$. Вычисленный из формулы (1) коэффициент подобия линейных размеров составляет от $10^{-5}$ до $10^{-6}$. Следовательно, 1 см модели соответствует 1 или 10 км природного объекта.

Модельный материал. При моделировании использовались студни оптически-активного материала - желатина (желатин фотографический активный, марки Б, низковязкий медленный). Применялись студни с концентрацией желатина $25 \%$. Свойства подобных моделей из желатина детально охарактеризованы в работе Д.Н. Осокиной [Osokina, 1963]. Основное требование к эквивалентному материалу - единообразие условий приготовления желатиновых студней, от которых зависят физикомеханические и оптические свойства моделей. В этой связи модели изготавливались по единой методике. В емкость с желатином добавлялось необходимое для получения соответствующей концентрации количество воды. Затем содержимое емкости расплавлялось на водяной бане при температуре $70{ }^{\circ} \mathrm{C}$. Получившийся однородный водно-желатиновый раствор заливался в специальную форму (размер - 0.05×0.30×0.45 м) для застывания и выдерживался в ней 24 часа. Моделирование осуществлялось на следующий день, через 1 час после извлечения студня из формы.

Оборудование, техника подготовки и проведения моделирования. Моделирование выполнено на установке «Деформатор», оснащенной полярископом-поляриметром ПКС-250, подробное описание которой представлено в работе [Bornyakov et al., 2014]. До начала эксперимента проводилась градуировка модели, в процессе которой определялось соотношение разности хода лучей (цвета модели) и максимальных касательных напряжений, величина которых вычисляется по формуле:

$$
\tau_{\text {max }}^{0}=\mathrm{P} / 2 \mathrm{~S},
$$

где $\tau^{0}{ }_{\text {max }}$ - величина касательных напряжений в модели без разрывов; Р - прилагаемая к модели нагрузка, S - площадь грани модели, на которую передается сжатие.

После градуировки в модель вносились неоднородности в виде вертикальных прорезей - модельных аналогов разломов. Методика позволяла вначале последовательно добавлять в модельный материал непротяженные разрывы, а затем увеличивать их длину. Поверхности каждой неоднородности смазывались водой для беспрепятственного скольжения берегов разрывов, так как именно смещение по разрывам изменяет (перераспределяет) напряжения в их окрестностях. Затем производилось деформирование модели и фоторегистрация областей распространения по площади разноцветных участков при скрещенных николях поляризатора и анализатора полярископа-поляриметра. Эти участки представляют собой набор цветных полос интерференции - изохром. Последние являются геометрическим местом точек с одинаковым значением максимальных касательных напряжений $\left(\tau_{\max }\right)$, которое соответствует половине разности величин главных нормальных напряжений, лежащих в плоскости модели. С помощью градуировочного графика возможно провести изолинии коэффициентов концентрации максимальных касательных напряжений:

$$
\mathrm{K}_{\tau}=\tau_{\max }^{\mathrm{i}} / \tau_{\text {max }}^{0}
$$

где $\tau^{\mathrm{i}}$ max - величина максимальных касательных напряжений в исследуемой точке модели с разрезами. Границы локальных максимумов $\left(\kappa_{\tau}>1\right)$ и минимумов $\left(K_{\tau}<1\right)$ проводились по центру соответствующих цветовых полос.

Эксперимент проводился в три этапа. На первом этапе в модели (1), расположенной между подвижным (2) и неподвижным (3) штампами установки, нарезалась сеть непротяженных разрывов одинаковой длины и ориентировки (4), имитирующая фрагмент зоны разлома на ранней стадии формирования (рис. $2, a$ ). На втором этапе три центральных разрыва были объединены в один протяженный разрыв, выполняющий роль магистрального шва в разломной зоне (рис. 2, б). На третьем этапе в центральный разрыв были вставлены две полоски бумаги, блокирующие смещение его крыльев под нагрузкой, что имитировало разделение магистрального шва в разломной зоне на активные и пассивные сегменты (рис. 2, в). На всех этапах модель подвергалась тангенциальному сжатию штампом (2), при котором на разрывах, в случае их деформационной активности, реализовывались левосторонние смещения. 
(a)

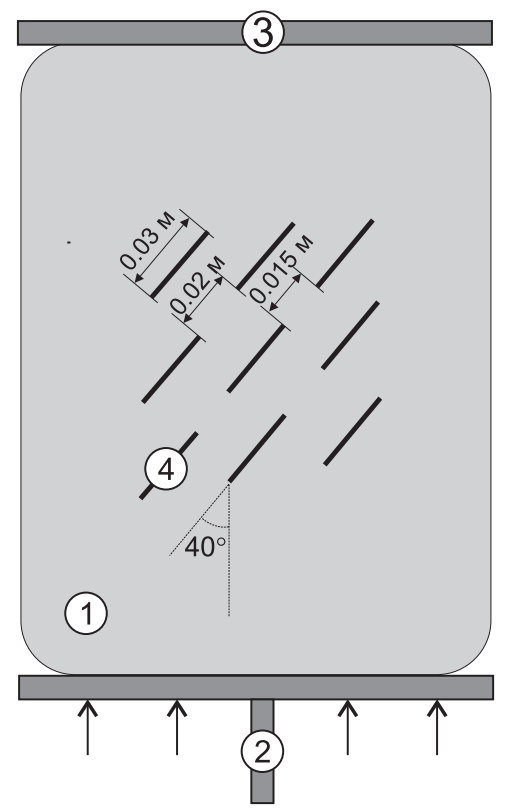

(б)

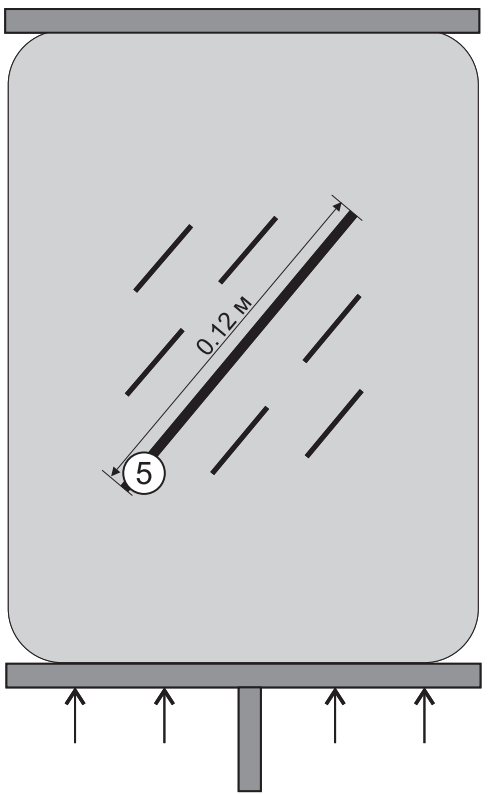

(8)

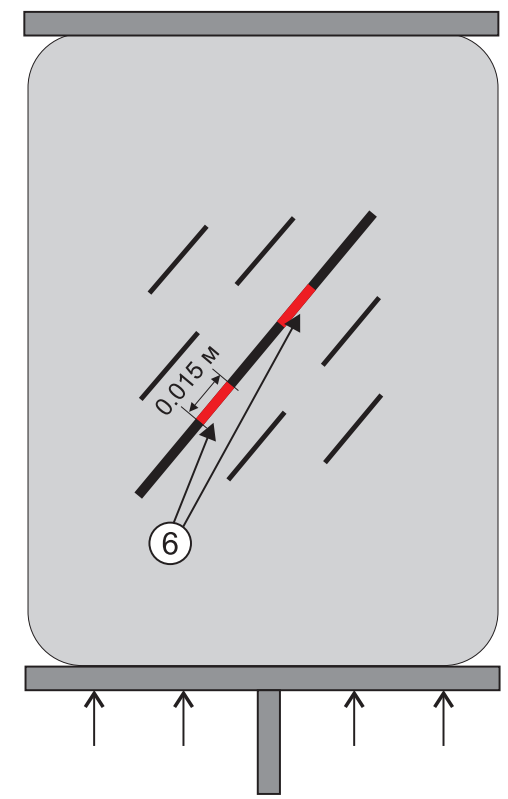

Рис. 2. Схемы разрывов в модели для первого (a), второго (б) и третьего (в) этапа эксперимента. 1 - модельный материал (студень желатина); 2 - подвижный и 3 - неподвижный штампы установки; 4 - система исходных разрывов; 5 - центральный объединенный разрыв; 6 - бумажные вставки в плоскости центрального разрыва.

Fig. 2. Schematic diagrams of the fault model for the first (a), second (6) and third ( 6 ) stages of the experiment. 1 - model material (gelatin); 2 - movable stamp; 3 - stationary stamp; 4 - system of initial ruptures; 5 - central joint rupture; 6 - paper markers in the central fault plane.

\section{3. МЕТОДЫ ОБРАБОТКИ}

Метод коррелящии цифровых изображений. Для обработки оптических изображений поверхности деформируемой модели из водной пасты использовался метод корреляции цифровых изображений (DIC, Digital Image Correlation) [Sutton et al., 2009], реализованный в ПО Strain Master (LaVision systems). Данный метод позволяет рассчитывать распределение компонент вектора перемещений, тензора деформаций и их эволюцию во времени [Panteleev et al., 2014]. Перед обработкой каждого изображения с помощью специализированных фильтров проводилась нормализация интенсивности пикселей по всей площади изображения для минимизации эффекта неравномерности освещения объекта съемки. Кроме того, все изображения калибровались по отдельному кадру с линейкой, что позволяло перейти к реальному пространственному масштабу объекта съемки и оперировать при восстановлении полей перемещений не пикселями, а миллиметрами.

Обработка изображений может проводиться по интегральному и дифференциальному сценариям. По интегральному сценарию оценка поля деформации модели проводится путем сравнения каждого кадра с первым кадром (исходное изображение).
Такой подход позволяет восстановить картину последовательного накопления деформации модели в процессе ее нагружения. По дифференциальному сценарию оценка поля деформации объекта съемки проводится путем последовательного сравнения двух соседних кадров, в результате чего оценивается приращение деформации модели съемки от кадра к кадру.

Нами использовался дифференциальный подход, позволяющий уточнить нелинейные, немонотонные особенности деформации объекта съемки. Для восстановления полей перемещений и деформаций использовались следующие параметры алгоритма корреляции цифровых изображений: режим корреляционного анализа - многопроходный с размером подобласти, варьируемым от $12.8 \times 12.8$ до $1.6 \times 1.6$ мм, размер шага - 50 \% от размеров подобласти, корреляционная функция - нормированная, второго порядка. На каждом временном шаге полученное поле скоростей сглаживалось двухмерным гауссовым фильтром размером 0.6×0.6 мм.

Для обработки был выбран 5-минутный интервал эксперимента, представленный 300 фотографиями верхней плановой поверхности модели.

Алгоритмы статистической обработки количественных параметров. Результаты обработки показали, что деформационный процесс в модели ре- 
ализуется в виде левосторонних смещений по всему разрыву или по его отдельным активным сегментам, а за его пределами - в виде локализованных пластических деформаций сдвига на двух сопряженных системах микросдвигов. По расчетным схемам распределения деформаций сдвига были составлены структурные схемы активных сегментов разрыва и пластических микросдвигов в его крыльях, и по каждой из них выполнены замеры их количества $(\mathrm{N})$ и длины $\left(\mathrm{L}_{\mathrm{i}}\right)$. По этим исходным параметрам впоследствии оценивались их суммарная $\left(\Sigma \mathrm{L}_{\mathrm{i}}\right)$ и средняя $\left(\mathrm{L}_{\text {midl }}=\Sigma \mathrm{L}_{\mathrm{i}} / \mathrm{N}\right)$ длина, угол наклона графика повторяемости $(\beta)$ и информационная энтропия $\left(\mathrm{S}_{\mathrm{i}}\right)$ по параметру $\mathrm{L}_{\mathrm{i}}$.

Угол наклона графика повторяемости оценивался методом максимального правдоподобия [Aki, 1965] по уравнению:

$$
\beta=\operatorname{lge} / \mathrm{L}_{\text {midl }}-\mathrm{L}_{\min },
$$

где е - основание натурального логарифма; $\mathrm{L}_{\text {midl }}$ средняя и $\mathrm{L}_{\min }$ - минимальная длина активных сегментов в выборке данных, собранных с анализируемой структурной схемы. Метод К. Аки адаптирован для анализа магнитуд землетрясений. Замена в уравнении (5) магнитуд землетрясений на длину активных сегментов допускается с учетом известной взаимосвязи длины сейсмогенных разломов с магнитудой землетрясений [Tocher, 1958; Golitsin, 1996].

Информационная энтропия оценивалась по известному уравнению [Zubarev et al., 2002]:

$$
\mathrm{S}_{\mathrm{i}}=-\sum \mathrm{p}_{\mathrm{i}} \cdot \lg \mathrm{p}_{\mathrm{i}}
$$

где $\mathrm{p}_{\mathrm{i}}$ - вероятность для і-того элемента анализируемой системы. В нашем случае $p_{i}$ соответствует вероятности появления активного сегмента і-той длины.

\section{4. РЕЗУЛЬТАТЫ}

\section{1. РЕЗУЛЬТАТЫ МОДЕЛИРОВАНИЯ ДЕФОРМАЦИОННОЙ ДИНАМИКИ РАЗРЫВА В УПРУГОВЯЗКОПЛАСТИЧНОЙ МОДЕЛИ}

Долговременная деформационная динамика разрыва. Результаты компьютерной обработки оптических изображений модели показали, что эволюция смещений по разрыву в упруговязкопластичной модели даже в условиях постоянной скорости ее нагружения реализуется по механизму прерывистого скольжения "stick-slip" [Brace, Byerlee, 1966]. За контрольный 300-секундный интервал произошло 47 импульсных подвижек разной интенсивно- сти, с временной дискретностью от пяти до десяти секунд. В моменты импульсной активизации происходит реализация смещений по всему разрыву или на большей его части, а между ними его активность сосредоточена на отдельных сегментах.

Для каждой из полученных 300 расчетных схем деформаций сдвига были составлены структурные схемы активных сегментов разрыва и собраны замеры их длины $\mathrm{L}_{\mathrm{i}}$ и по ним оценены суммарная длина $(\Sigma \mathrm{L})$, угол наклона графика повторяемости $(\beta)$ и информационная энтропия $\left(\mathrm{S}_{\mathrm{i}}\right)$. Графическое представление полученных оценок приведено на рис. 3.

\section{2. КРАТКОВРЕМЕННАЯ ДЕФОРМАЦИОННАЯ ДИНАМИКА КРУПНОГО РАЗРЫВА В УПРУГОВЯЗКОПЛАСТИЧНОЙ МОДЕЛИ МЕЖДУ ЕГО ПОЛНЫМИ АКТИВИЗАЦИЯМИ}

Эволюция смещений по крупному разрыву между его полными активизациями. На рис. 4 в качестве примера показана деформационная динамика разрыва с посекундной дискретизацией от одной полной активизации до другой, что в природе соответствует сейсмическому циклу. Под полной активизацией понимается активизация разрыва по всей длине в пределах используемой для расчетов рабочей площадки (см. рис. 1, символ 10). Из представленных схем видно, что после первой активизации (рис. 4, A, A') смещения на разрыве происходят фрагментарно на нескольких относительно крупных сегментах (рис. 4, Б, Б'). В последующих шести временных интервалах крупные сегменты дробятся на серию более мелких, что выражается в увеличении их количества с сокращением их средней и суммарной длины и увеличением угла наклона графика повторяемости, рассчитанного методом максимального правдоподобия по длинам сегментов (табл. 2; рис. 4, В'-Ж'). Перед очередной полной активизацией процесс сегментации стабилизируется (табл. 2; рис. 4, 3, 3'), затем приобретает обратную направленность, с противоположным изменением перечисленных параметров (табл. 2; рис. 4, И, И').

Кратковременная динамика деформаций в крыльях разрыва между его полными активизациями. На рис. 5 представлен фрагмент рисунка 4 К, отражающий распределение деформации сдвига в другой цветовой палитре, более отчетливо показывающей наличие многочисленных сопряженных пластических микросдвигов двух простираний в крыле разрыва, проявленных в виде линейно локализованных максимумов деформации сдвига. Для фрагментов верхнего крыла разрыва схем А-К были составлены схемы проявленных в их пределах микросдвигов и по аналогии с активными сегментами выполнены замеры их количества и длины, с 
(a)

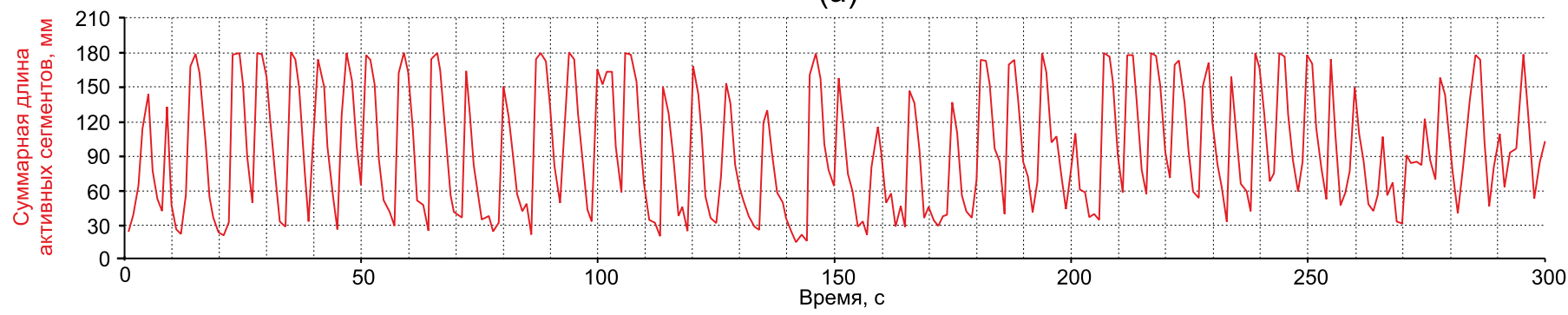

(б)

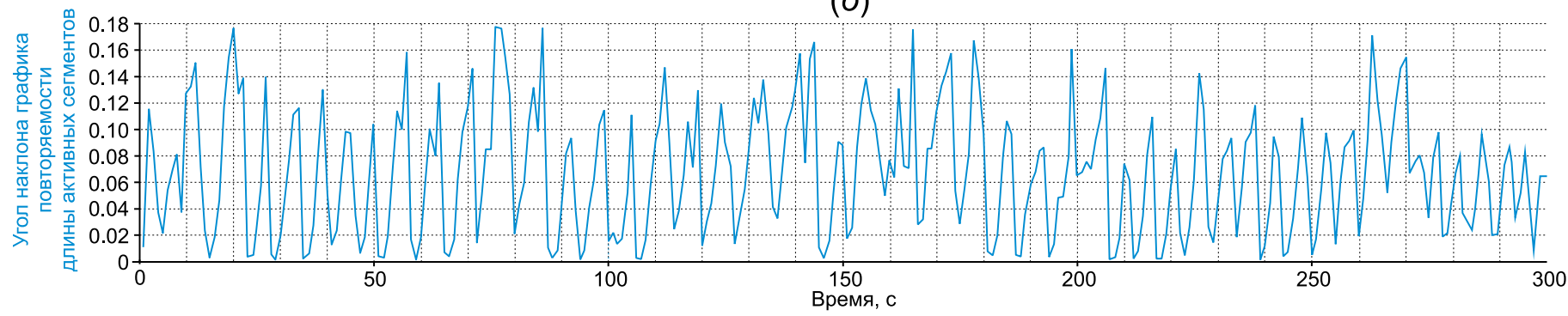

$(8)$

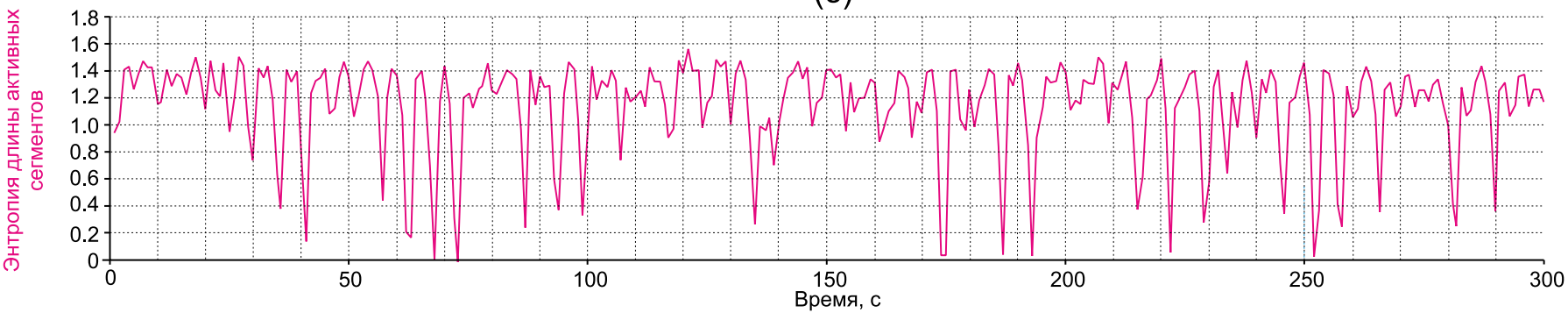

Рис. 3. Изменение во времени суммарной длины $(a)$, угла наклона графика повторяемости (б) и информационной энтропии (в) активных сегментов разрыва.

Fig. 3. Temporal changes in the total length $(a)$, repeatability curve dip angle (б) and information entropy $(8)$ of the active segments of the fault.

последующей оценкой суммарной и средней длины, угла наклона графика повторяемости и информационной энтропии (табл. 3).

\section{3. РЕЗУЛЬТАТЫ ОПТИЧЕСКОГО МОДЕЛИРОВАНИЯ ПОЛЯ НАПРЯЖЕНИЙ В ОБЛАСТИ ДИНАМИЧЕСКОГО ВЛИЯНИЯ РАЗРЫВА ПРИ ЕГО СЕГМЕНТАЦИИ}

Результаты трехэтапного моделирования приведены на рис. 6. На первом этапе эксперимента в модели была воспроизведена серия непротяженных разрывов одинаковой длины и ориентировки, имитирующая зону разлома на ранней дизъюнктивной стадии формирования [Seminsky, 2003]. Без нагрузки касательные напряжения в моделях отсутствуют. С началом нагружения модели начинаются левосторонние смещения берегов разрывов, в результате чего в их окрестностях наблюдаются практически одинаковые по величине области концентрации $\tau_{\max }$ (рис. 6, A, A'). Некоторое увели- чение $\tau_{\max }$ у разрывов центральной части, повидимому, связано с взаимодействием дислокаций, которые расположены на продолжении друг друга. В связи с тем, что перемычки между этими дислокациями небольшие, наблюдается объединение концевых максимумов.

На втором этапе опыта три центральных разрыва объединены в протяженную структуру, что имитировало образование единого магистрального шва в сдвиговой зоне. После такого объединения вся активность сосредоточилась на этом разрыве, что привело к снижению уровня касательных напряжений в центральной части моделируемой структуры и переходу ранее активных непротяженных разрывов в пассивное состояние (рис. 6, Б, Б').

На третьем этапе эксперимента имитировался процесс сегментации объединенного центрального разрыва путем помещения в его плоскость двух полосок сухой бумаги, препятствующих скольжению крыльев. Результатом такой искусственной «сегментации» явился рост напряжений в его окрест- 


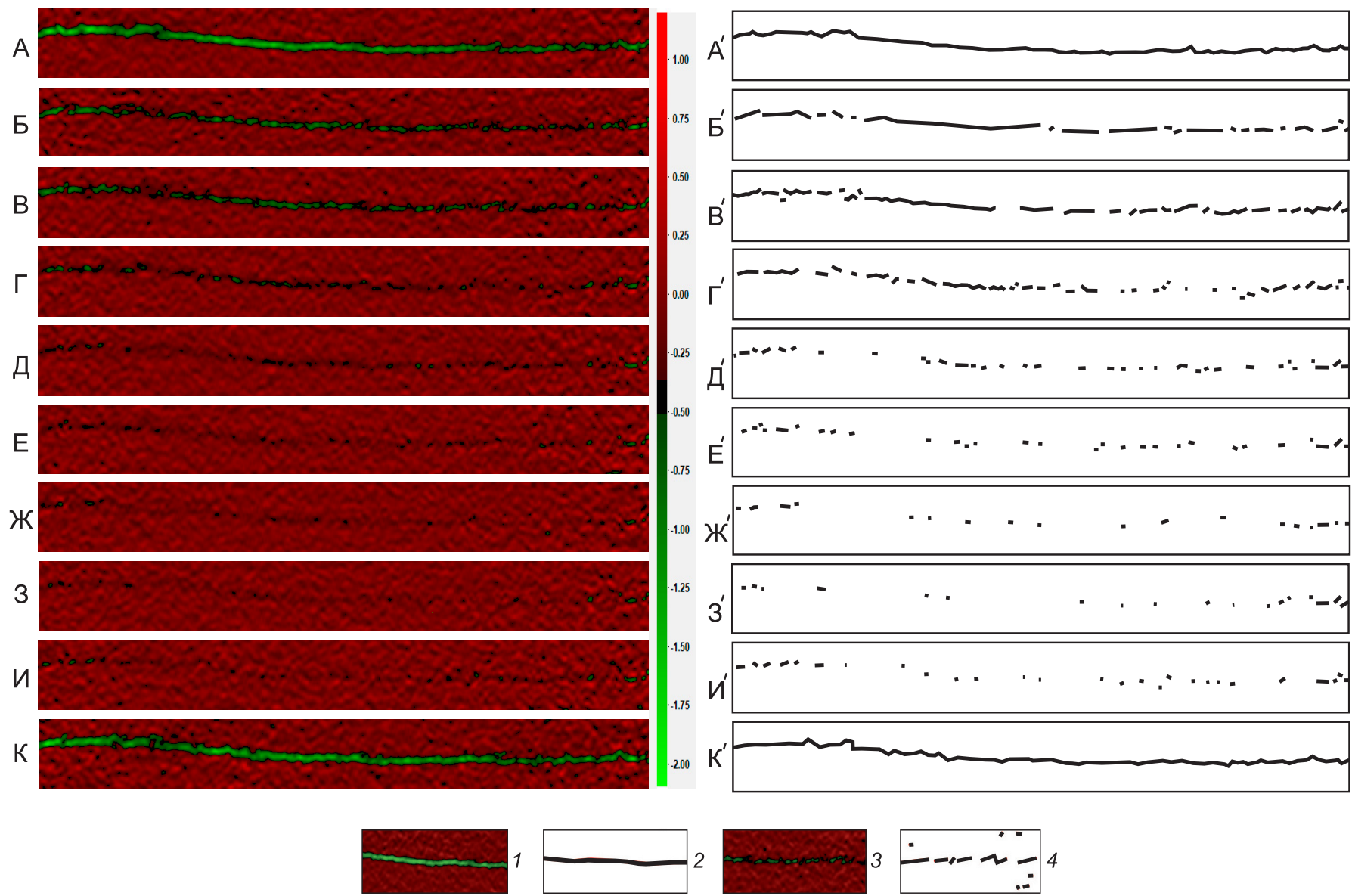

Рис. 4. Эволюция структуры активных сегментов разрыва в модели между двумя его полными активизациями. 1 активный разрыв в модели по результатам обработки методом DIC; 2 - активный разрыв на схеме; 3 - совокупность активных сегментов в модели по результатам обработки методом DIC; 4 - совокупность активных сегментов на схеме.

Fig. 4. Structure evolution of active fault segments in the model between two full activations. Active fault segment: 1 - DIC processing result; 2 - diagram. Cluster of active fault segments: 3 - DIC processing result; 4 - diagram.

\section{Т а б л и ц а 2. Изменение параметров сегментов разрыва между двумя его полными активизациями}

\section{$\mathrm{T} \mathrm{a} \mathrm{b} \mathrm{l}$ e 2. Changes in the parameters of the fault segments between two full activations}

\begin{tabular}{llllll}
\hline Время, с & $\begin{array}{l}\text { Количество } \\
\text { сегментов }\end{array}$ & $\begin{array}{l}\text { Суммарная длина } \\
\text { сегментов }\end{array}$ & $\begin{array}{l}\text { Средняя длина } \\
\text { сегментов }\end{array}$ & $\begin{array}{l}\text { Угол наклона графика } \\
\text { повторяемости для длин сегментов }\end{array}$ & $\begin{array}{l}\text { Информационная } \\
\text { энтропия длин сегментов }\end{array}$ \\
\hline 0 (ПА) & 1 & 180 & 180 & - & - \\
1 & 24 & 164 & 3.1 & 0.15 & 0.11 \\
2 & 36 & 109 & 1.1 & 0.39 & 0.16 \\
3 & 36 & 128 & 1.2 & 0.38 & 038 \\
4 & 34 & 78 & 0.7 & 0.55 & 0.52 \\
5 & 28 & 48 & 0.35 & 111 & 1.39 \\
6 & 18 & 30 & 0.3 & 1.4 & 1.54 \\
7 & 18 & 29 & 0.35 & 1.52 & 0.87 \\
8 & 27 & 49 & 0.4 & 0.93 & - \\
9 (ПА) & 1 & 180 & 180 & - & \\
\hline
\end{tabular}

П р и м е ч а н и е. ПА - полная активизация.

$\mathrm{N}$ o t e. ПА - full activation. 
(a)
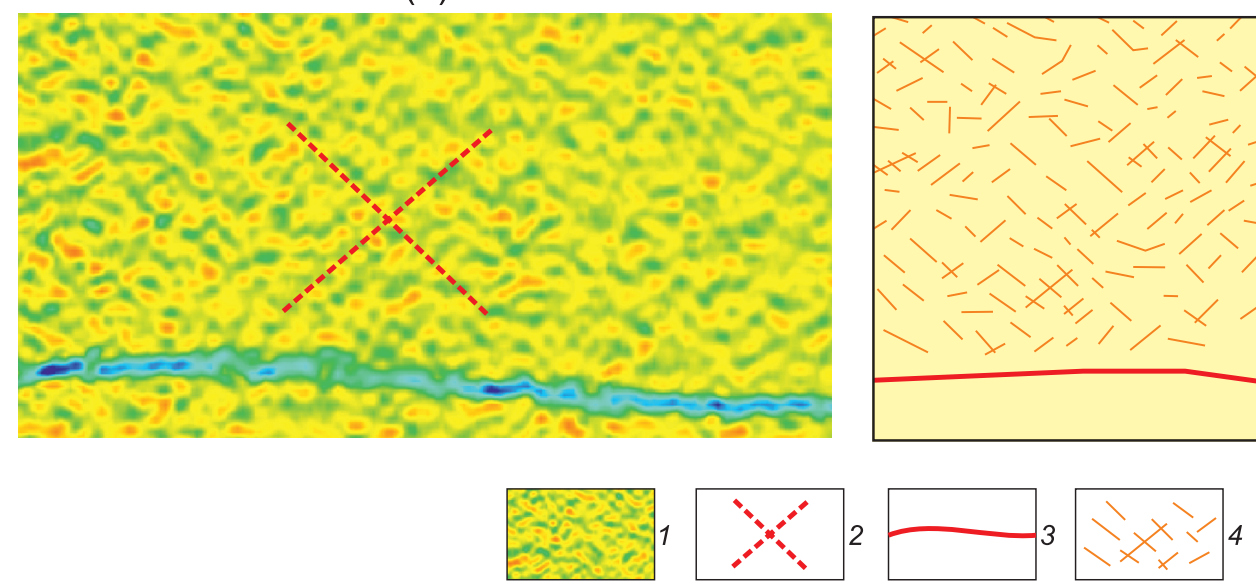

(б)

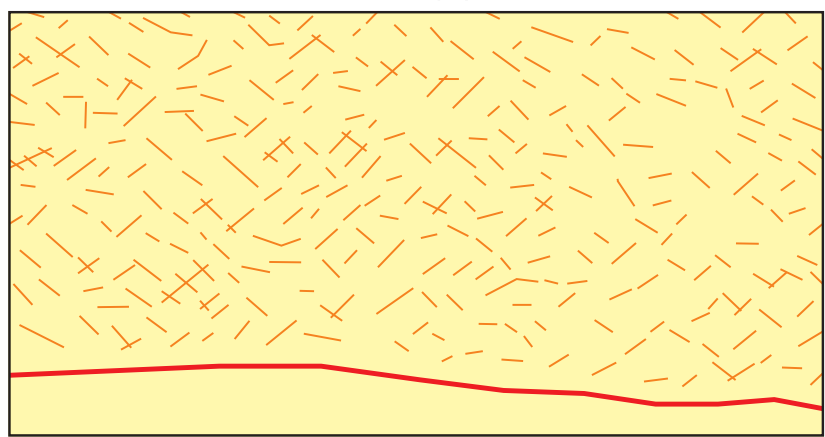

Рис. 5. Пластические микросдвиги в крыле разрыва в модели (a) и их структурная схема (б). 1 - полосовидные максимумы значений деформации сдвига, соответствующие пластическим микросдвигам; 2 - два основных простирания микросдвигов; 3 - разрыв и 4 - пластические микросдвиги на структурной схеме.

Fig. 5. Plastic microslip faults in the fault wing. (a) - model: 1 - bands of maximum values of shear deformation corresponding to plastic micro slipfaults; 2 - two main strikes of microslip faults. (6) - structure diagram: 3 - fault; 4 - plastic microslip faults.

ностях и переход пассивных разрывов в активное состояние (рис. 6, В, В').

\section{5. ОБСУЖДЕНИЕ РЕЗУЛЬТАТОВ}

\section{1. ДОЛГОВРЕМЕННАЯ ДЕФОРМАЦИОННАЯ ДИНАМИКА РАЗРЫВА}

Как было показано выше, эволюция смещений по существующему разрыву в упруговязкопластич- ной модели даже в условиях постоянной скорости ее нагружения протекает неравномерно по механизму прерывистого скольжения "stick-slip" [Brace, Byerlee, 1966]. В моменты импульсных активизаций происходит реализация смещений по всему разрыву или на большей его части (см. рис. 4, A, A', К, К'), а между такими активизациями смещения сосредоточены на отдельных сегментах (см. рис. 4, Б-И, Б'-И').

Рассматривая развивающийся в модели процесс "stick-slip" с позиции повторяющейся самооргани-

\section{T а б л и ц а 3. Изменение параметров пластических микросдвигов в крыльях разрыва между двумя его} полными активизациями

$\mathrm{T}$ a $\mathrm{b}$ l e 3 . Changes in the parameters of plastic microslip faults in the fault wings between two full activations

\begin{tabular}{llllll}
\hline Время, с & $\begin{array}{l}\text { Количество } \\
\text { микросдвигов }\end{array}$ & $\begin{array}{l}\text { Суммарная длина } \\
\text { микросдвигов, мм }\end{array}$ & $\begin{array}{l}\text { Средняя длина } \\
\text { микросдвигов, мм }\end{array}$ & $\begin{array}{l}\text { Угол наклона графика } \\
\text { повторяемости для длины } \\
\text { микросдвигов }\end{array}$ & $\begin{array}{l}\text { Информационная } \\
\text { энтропия для длин } \\
\text { микросдвигов }\end{array}$ \\
\hline 0 (ПА) & 210 & 2200 & 10.48 & 0.097 & 2.245 \\
1 & 162 & 1490 & 9.2 & 0.120 & 2.180 \\
2 & 202 & 1990 & 9.85 & 0.103 & 2.240 \\
3 & 255 & 2615 & 10.26 & 0.091 & 2.325 \\
4 & 260 & 2600 & 10.0 & 0.099 & 2.234 \\
5 & 272 & 2280 & 9.91 & 0.051 & 2.237 \\
6 & 235 & 2400 & 9.7 & 0.089 & 2.22 \\
7 & 231 & 2900 & 10.39 & 0.078 & 2.23 \\
8 & 279 & 2345 & 10.39 & 0.065 & 2.238 \\
$9(П А)$ & 268 & & & 0.080 & 2.236 \\
\hline
\end{tabular}

П р и м е ч а н и е. ПА - полная активизация.

$\mathrm{N}$ o t e. ПА - full activation. 
(a)

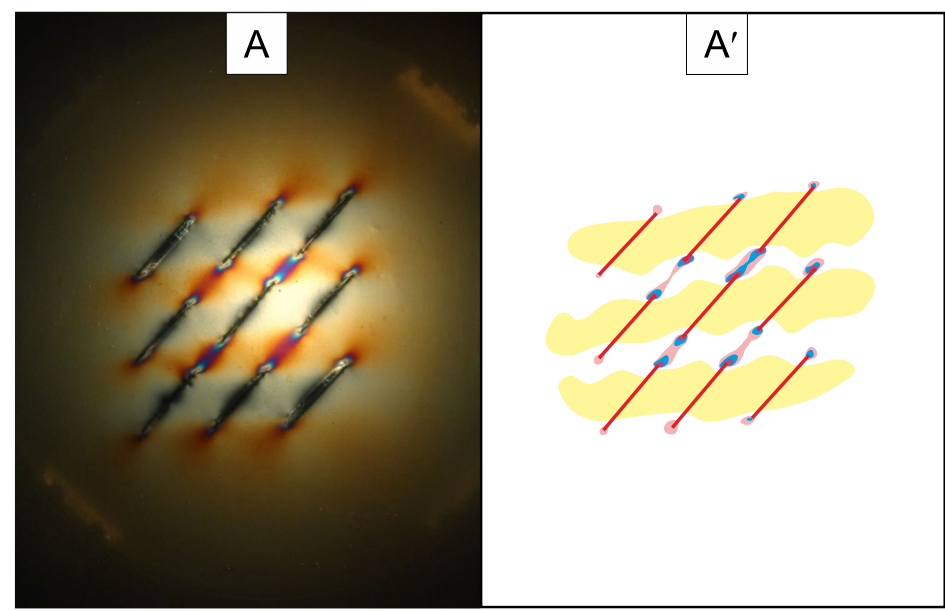

(б)

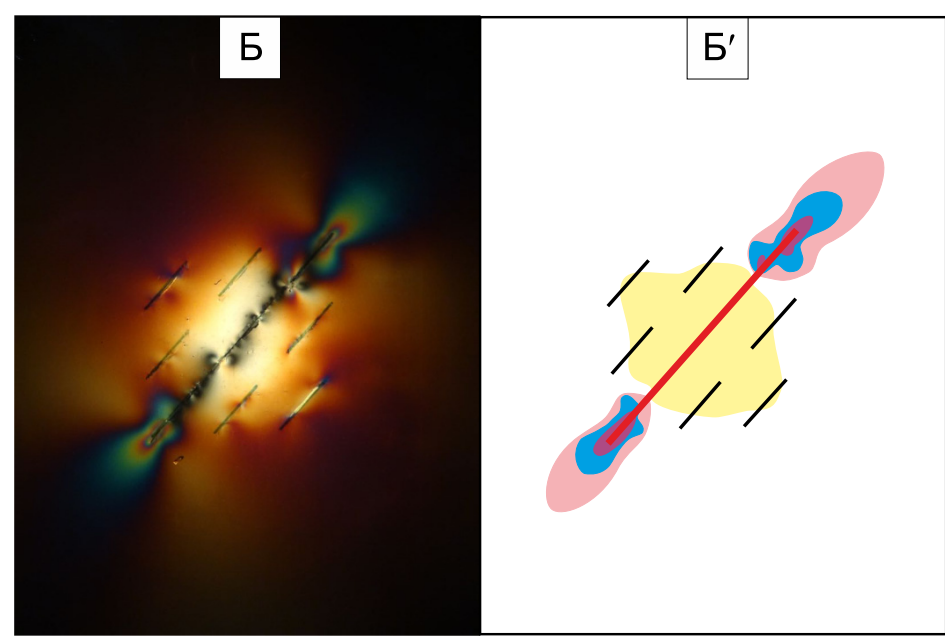

(в)
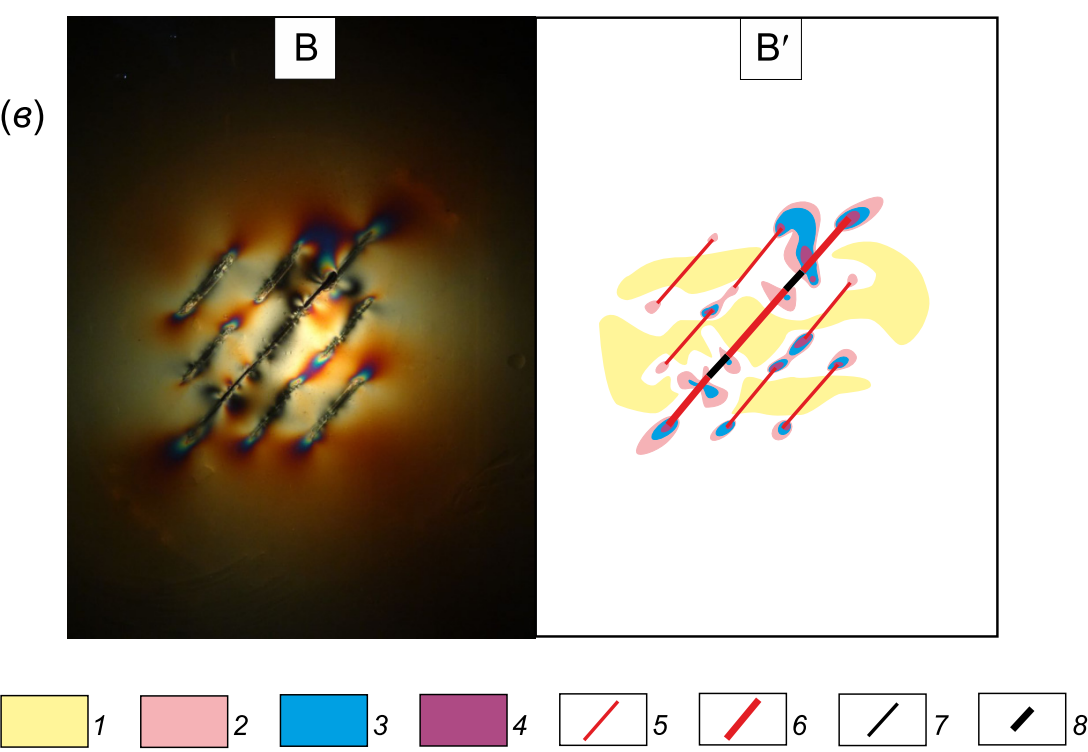

Рис. 6. Результаты поляризационно-оптического моделирования напряженного состояния в зоне разлома. (a) - система непротяженных разрывов одинаковой длины; (б) - непротяженные разрывы в зоне активного крупного разлома; (в) - непротяженные разрывы в зоне сегментированного крупного разлома.

1-4 - коэффициент концентрации $\tau_{\max } 1-\kappa_{\tau}<0.75,2-K_{\tau}=1.25-1.50,3-K_{\tau}=1.5-2.0,4-K_{\tau}>2 ; 5$ - активные непротяженные разрывы; 6 - активные сегменты основного центрального разрыва; 7 - пассивные непротяженные разрывы; 8 - пассивные сегменты основного центрального разлома.

Fig. 6. Results of polarization-optical modeling of the stress state in the fault zone. (a) - system of short ruptures of similar lengths; (б) - short ruptures in the zone of the active large fault; ( 8$)$ - short ruptures in the zone of the segmented large faults.

1-4 - concentration coefficient $\tau_{\max }: 1-K_{\tau}<0.75,2-K_{\tau}=1.25-1.50,3-K_{\tau}=1.5-2.0,4-K_{\tau}>2 ; 5$ - active short ruptures; 6 - active segments of the main central fault; 7 - passive short ruptures; 8 - passive segments of the main central fault. 
зованной критичности [Bak, Tang, 1989], следует ожидать, что непосредственно перед полными активизациями разрыва, по мере достижения критического уровня напряжений на плоскости его сместителя, система активных сегментов должна переходить в состояние самоорганизации [Ma et al., 2012, 2014], а последней будет предшествовать ее хаотизация. Показателем степени хаотичности систем является термодинамическая энтропия или ее статистический аналог - информационная энтропия $\mathrm{S}_{\mathrm{i}}$ [Zubarev et al., 2002; Gudmundsson, Mohajeri, 2013].

Из анализа экспериментальных данных по акустической эмиссии от нагружаемых образцов горных пород и анализа сейсмичности в очагах сильных землетрясений известно, что параметр $\beta$ отражает уровень напряжений и связан с ним обратной зависимостью [Amitrano, 2003; Berg, 1968; Goebel et al., 2017; Nanjo et al., 2012; Rivière et al., 2018; Scholz, 1968].

Вариации параметров $\beta$ и $\mathrm{S}_{\mathrm{i}}$ во времени согласуются с приведенными выше рассуждениями (см. рис. 3). Моментам полной активизации разрыва, соответствующим максимальным значениям $\Sigma \mathrm{L}$, в $74 \%$ случаев соответствуют минимальные значения $\beta$ и в 76 \% случаев - максимальные значения $\mathrm{S}_{\mathrm{i}}$.

\section{2. КРАТКОВРЕМЕННАЯ ДЕФОРМАЦИОННАЯ ДИНАМИКА РАЗРЫВА}

Детали эволюции активных сегментов разрыва, а также пластических сдвигов в области его динамического влияния хорошо прослеживаются на более коротком временном интервале по изменению их параметров, представленных в таблицах 2 и 3 и отображенных графически (рис. 7). В этих изменениях выделяется два основных тренда, позволяющих разделить деформационный процесс на регрессивную и прогрессивную фазы, укладывающиеся во временные интервалы 0-7 с и 7-9 с соответственно. Прогрессивная фаза деформационного процесса по длительности существенно короче регрессивной и в разных случаях составляет первые секунды. При этом, чем она короче, тем интенсивнее и полнее проявляется активизация разрыва, и, наоборот, с увеличением ее продолжительности интенсивность активизации разрыва снижается, и он чаще всего активизируется не по всей своей длине.

В первую фазу происходит постепенное вырождение сегментной структуры разрыва за счет направленного дробления крупных сегментов на более мелкие с переходом некоторых из них в пассивное состояние, что находит отражение в уменьшении их количества, суммарной и средней длины (см. рис. $7, a, 6,8)$. Рост значений $\beta$ и $S_{i}$ показывает, что процесс сегментации в эту фазу реализуется на фоне релаксационного снижения уровня напряжений и повышения степени хаотичности в распределении сегментов по длине (см. рис. 7, 2, д). К концу регрессивной фазы деформационного процесса активность разрыва сосредоточена на коротких сегментах, стремящихся к равномерному распределению по его простиранию. С началом прогрессивной фазы, в условиях роста напряжений, количество активных сегментов сначала возрастает до некоторой критической плотности с увеличением их хаотичности, затем уменьшается за счет их быстрого разрастания и объединения в более крупные, вплоть до единого разрыва в момент его полной активизации. Эволюционный процесс в прогрессивную фазу в общих чертах соответствует модели лавинонеустойчивого трещинообразования (ЛНТ) [Myachkin et al., 1975], с той лишь разницей, что в нашем случае роль новообразованных трещин играют разрастающиеся и избирательно объединяющиеся между собой активные сегменты.

Из сопоставления графиков параметров активных сегментов и пластических микросдвигов следует, что динамика деформационных процессов на разрыве и в области его динамического влияния различается (рис. 7). Особенно отчетливо это различие проявляется в поведении параметров $\Sigma \mathrm{L}, \mathrm{l}_{\mathrm{midl}}$ и $\beta$. После первой полной активизации разрыва количество, суммарная и средняя длина пластических микросдвигов кратковременно уменьшаются на фоне роста $\beta$ и $S_{\text {i }}$ (рис. 7). В дальнейшем, вплоть до следующей полной активизации разрыва, значения параметров $\mathrm{N}, \Sigma \mathrm{L}, \mathrm{l}_{\mathrm{midl}}$ и $\mathrm{S}_{\mathrm{i}}$ с небольшими вариациями в целом возрастают, а $\beta$ - уменьшается. При этом изменения параметров $\Sigma \mathrm{L}, \mathrm{l}_{\text {midl }}$ и $\beta$ у сегментов и пластических микросдвигов происходят почти в противофазе. Как показали результаты оптического моделирования, это связано с особенностями вариаций уровня напряжений в области динамического влияния разрыва при разной степени его активности (см. рис. 6). Напряжения в ней снижаются при полной активизация разрыва (см. рис. 6, б) и существенно повышаются при переходе от полной его активности к сегментной (рис. 6, в). При этом, как следует из вариаций $\beta$, увеличение напряжений в крыльях разрыва начинается в начале регрессивной фазы. На самом же разрыве их интенсивный однонаправленный рост проявляется намного позже только в прогрессивную фазу (рис. $7,2)$.

Из различий в динамике деформаций в плоскости разрыва и в области его динамического влияния следует важный с точки зрения прогнозных построений вывод о том, что анализ сейсмичности в потенциальной очаговой области следует проводить, разделяя выборку землетрясений по пространственной принадлежности к собственно зоне 
(a)

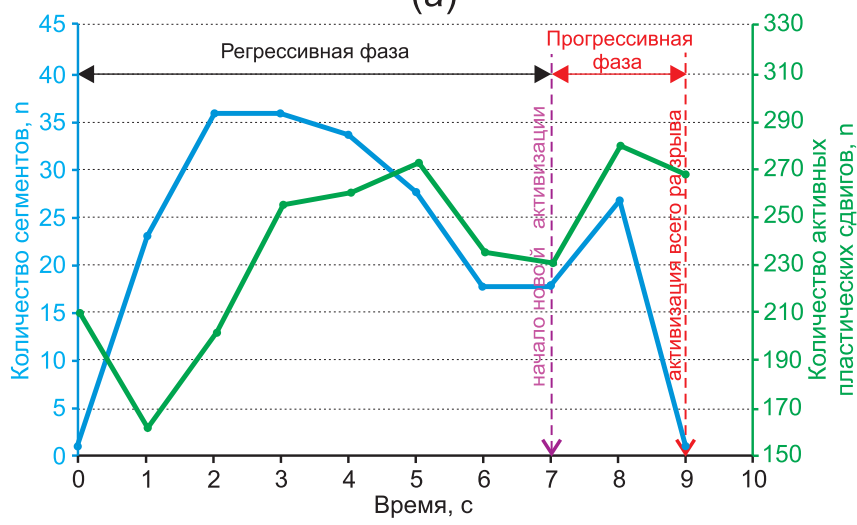

$(8)$

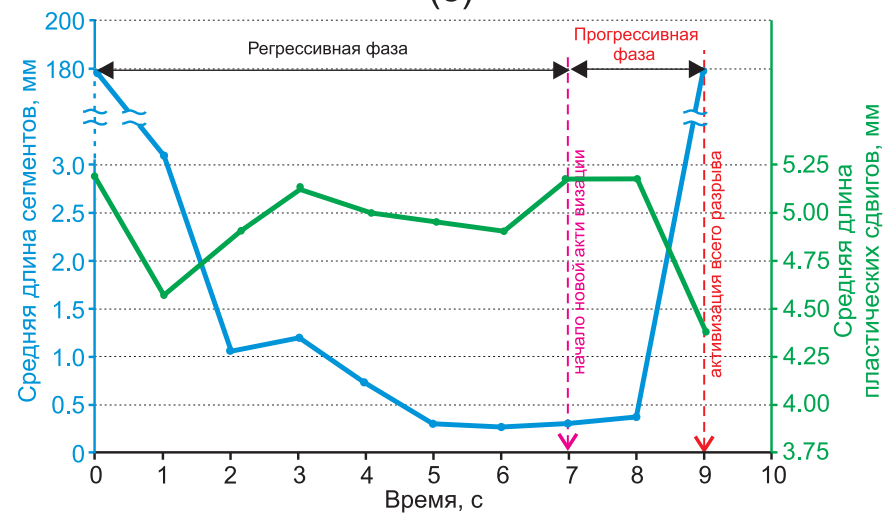

(б)

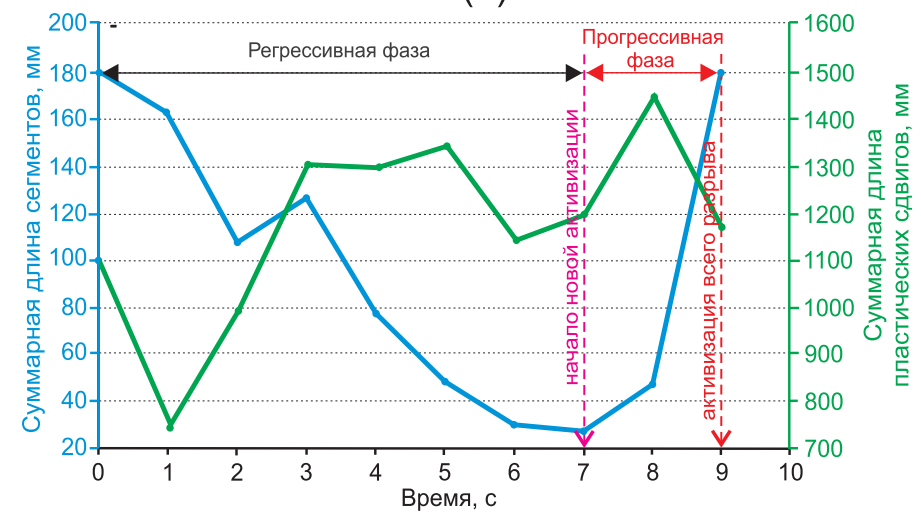

(2)

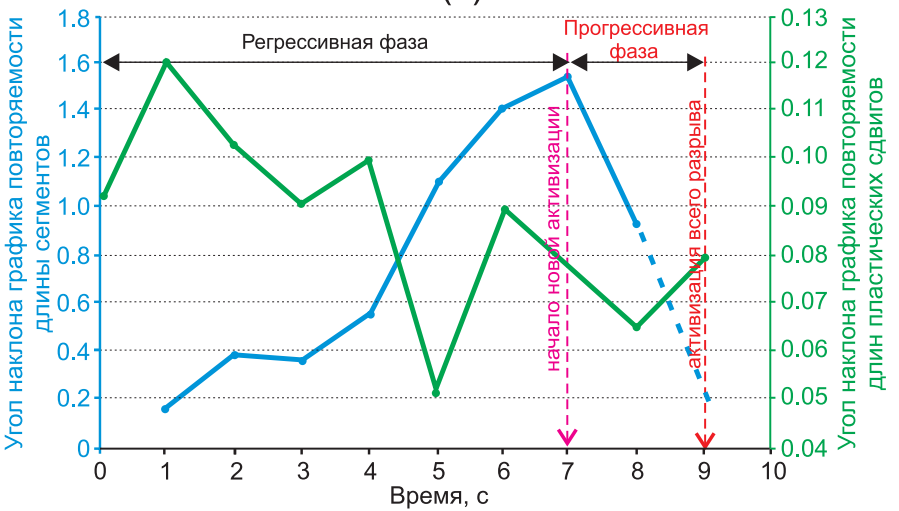

$(\partial)$

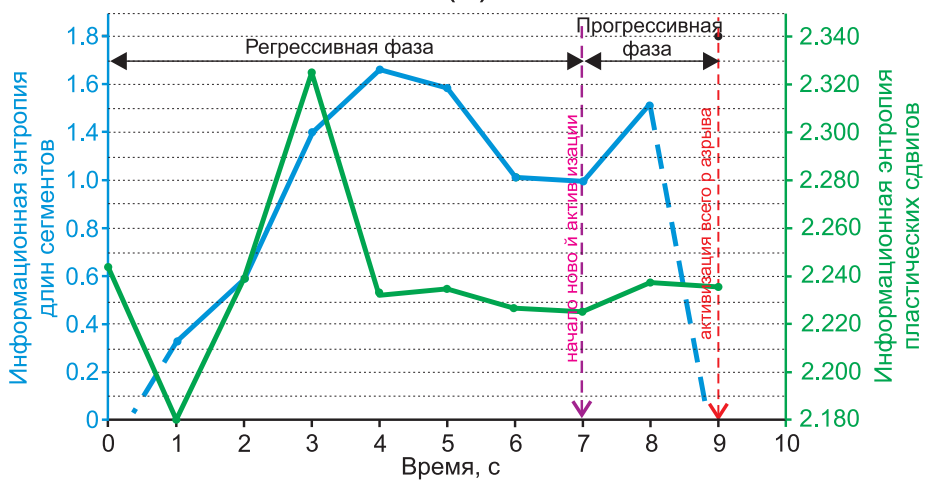

Рис. 7. Вариации количества сегментов (a), их суммарной (б) и средней (в) длины, угла наклона графика повторяемости (2) и информационной энтропии (д).

Fig. 7. Variations in the number of segments $(a)$, their total (б) and mean ( $(8)$ lengths, repeatability curve dip angle (2), and information entropy $(\partial)$.

сейсмоактивного разлома и к приразломной области. В этой связи необходимо оценить ширину каждой из них.

\section{3. ВАРИАЦИИ ШИРИНЫ ОБЛАСТИ ДИНАМИЧЕСКОГО ВЛИЯНИЯ КРУПНОГО РАЗЛОМА ПРИ ЕГО ПЕРИОДИЧЕСКОЙ АКТИВИЗАЦИИ}

Зоны крупных разломов представляют собой объемные тела с определенным структурно-вещественным наполнением [Sherman et al., 1983,
1991; Seminsky, 2003; Choi et al., 2016]. Для их характеристики С.И. Шерманом предложено понятие «область динамического влияния разлома (ОДВР)» [Sherman et al., 1983, 1991]. По определению ОДВР представляет собой трехмерную область, в которой проявляются упругие и остаточные (пластические и разрывные) деформации, связанные с формированием разлома и последующими подвижками по нему. Для характеристики пространственного распространения только остаточных деформаций им же предложено понятие «области активного дина- 


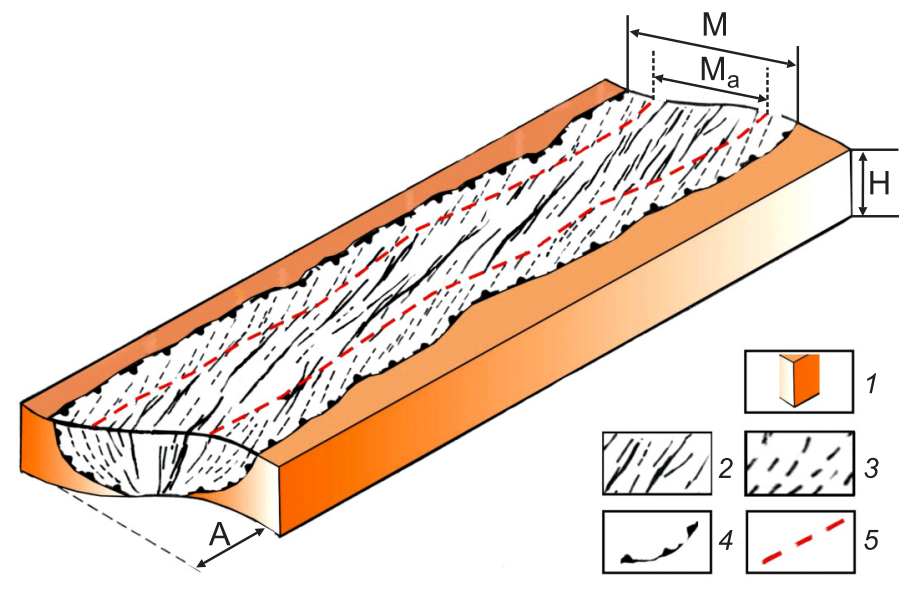

Рис. 8. Структурная схема ОАДВ сдвиговой зоны в модели. Н - толщина модели; А - амплитуда смещения крыльев зоны разлома; М - ширина ОАДВ; $\mathrm{M}_{\mathrm{a}}$ - ширина ОАCP.

1 - модель; 2 - активные разрывы; 3 - пассивные разрывы; 4 - граница ОАДВР; 5 - граница ОАСР.

Fig. 8. Structural diagram of the zone of active dynamic influence of the strike-slip fault (ZADIF) in the model. $\mathrm{H}$ thickness of the model; $A$ - displacement amplitude of the wings of the fault zone; $M-$ ZADIF width; $M_{a}$ - width of the active strike-slip fault zone.

1 - model; 2 - active ruptures; 3 - passive ruptures; 4 - ZADIF boundary; 5 - boundary of the active strike-slip fault zone.

мического влияния разлома (ОАДВР)» (рис. 8). Наблюдения за формированием зон крупных разломов разных морфолого-генетических типов в упруговязкопластичных моделях литосферы показали, что к концу первой стадии развития ОАДВР достигает максимальной ширины (M) [Sherman et al., 1991; Seminsky, 2003; Bornyakov et al., 2014], описываемой уравнением:

$$
\mathrm{M}=\mathrm{C}_{1} \cdot \mathrm{H}+\mathrm{C}_{2} \cdot \lg \eta+\mathrm{C}_{3} \cdot \lg \mathrm{V}-\mathrm{K},
$$

где $\mathrm{H}, \eta, \mathrm{V}$ - толщина модели, ее вязкость и скорость нагружения соответственно, $\mathrm{C}_{1}, \mathrm{C}_{2}, \mathrm{C}_{3}$, К - коэффициенты, определяемые морфолого-генетическим типом разломной зоны.

Установлено, что параметр М главным образом определяется толщиной модели, связан с ней прямой зависимостью и по экспериментальным оценкам в целом составляет (1.0-1.5) H [Sherman et al., 1991]. В приложении к природной ситуации это означает, что зона крупного разлома, формирующаяся в литосфере толщиной 100 км, будет иметь ширину его ОАДВ 100-150 км.

Как отмечено выше, параметр М отражает максимальную ширину ОАДВР. В ходе дальнейшей эволюции зоны разлома процесс разрывообразо- вания локализуется во все более узкой области. Для характеристики этой области введено понятие «область активного структурообразования разлома (ОАСР)» $\left(\mathrm{M}_{\mathrm{a}}\right)$ (рис. 8) и предложено уравнение оценки ее ширины. Для сдвиговой зоны оно имеет вид [Bornyakov, 1990]:

$$
\begin{aligned}
\mathrm{M}_{\mathrm{a}}= & 0.9525 \mathrm{H}-0.02701 \mathrm{~A}-0.0758 \lg \eta+ \\
& +0.4161 \lg \mathrm{l}+4.4924
\end{aligned}
$$

Из уравнения следует, что параметр $\mathrm{M}_{\mathrm{a}}$ в основном определяется толщиной разрушаемого слоя $(\mathrm{H})$ и амплитудой смещения крыльев разлома $(\mathrm{A})$ при незначительном влиянии его вязкости (П) и скорости деформирования (V). При этом Н и А выполняют разные функции. Если первый параметр определяет максимально возможное значение параметра $\mathrm{M}_{\mathrm{a}}$ в пределе равное $\mathrm{M}$, то второй контролирует его последующие изменения по мере развития деформационного процесса. ОАСР достигает минимальной величины к концу третьей стадии, когда сформируется один крупный магистральный разрыв, а все другие разрывы меньшего масштабного ранга, попавшие в его ОАДВ, перейдут в пассивное состояние (рис. 9, а, б) [Bornyakov, 1990; Seminsky, 2003]. Минимальная ширина ОАС магистрального разрыва в модели колеблется от 2-3 до 10 мм, что в пересчете через коэффициент подобия линейных размеров составляет от 2-3 до 10 км. Эти оценки согласуются с оценками ширины зон разломов, сделанными по полевым наблюдениям [Choi et al., 2016].

В случае прекращения смещений на каком-то участке магистрального разрыва в условиях продолжающегося смещения крыльев разломной зоны, то есть в случае появления на нем пассивного сегмента, в пределах последнего начинается рост напряжений с соответствующим реверсивным расширением его ОАДВ и активизацией в ней разрывов (см. рис. 6, В, В'; рис. 9, в). Пределом такого расширения, как отмечено выше, является ширина М ОАДВР.

Таким образом, опираясь на экспериментально полученные оценки параметров, можно констатировать, что ширина ОАДВ крупных сейсмоактивных разломов в сейсмических зонах литосферы оценивается в 100-150 км, а ширина их шовных зон, ответственных за основную сейсмогенерацию, - в 2-10 км.

\section{6. ЗАКЛЮЧЕНИЕ}

Выполнено физическое моделирование процесса прерывистого скольжения по существующему крупному разлому в упруговязкопластичной и 
(a)

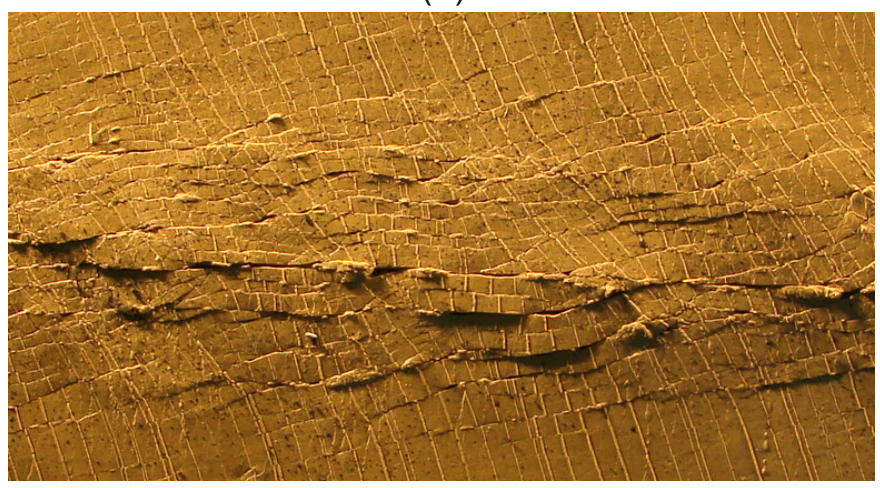

(б)
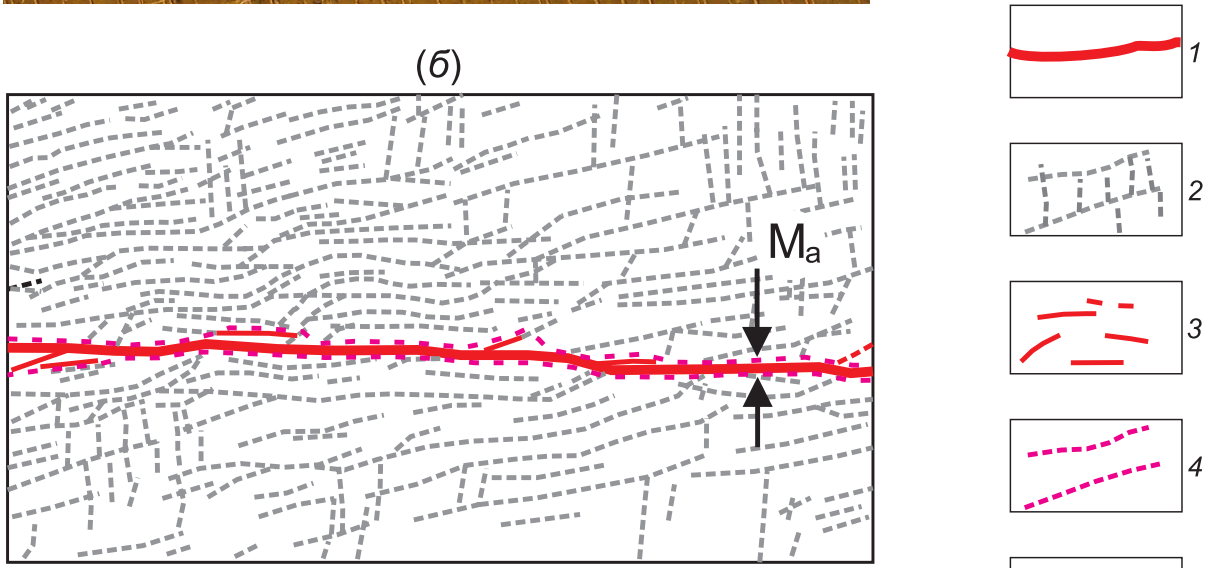

(8)
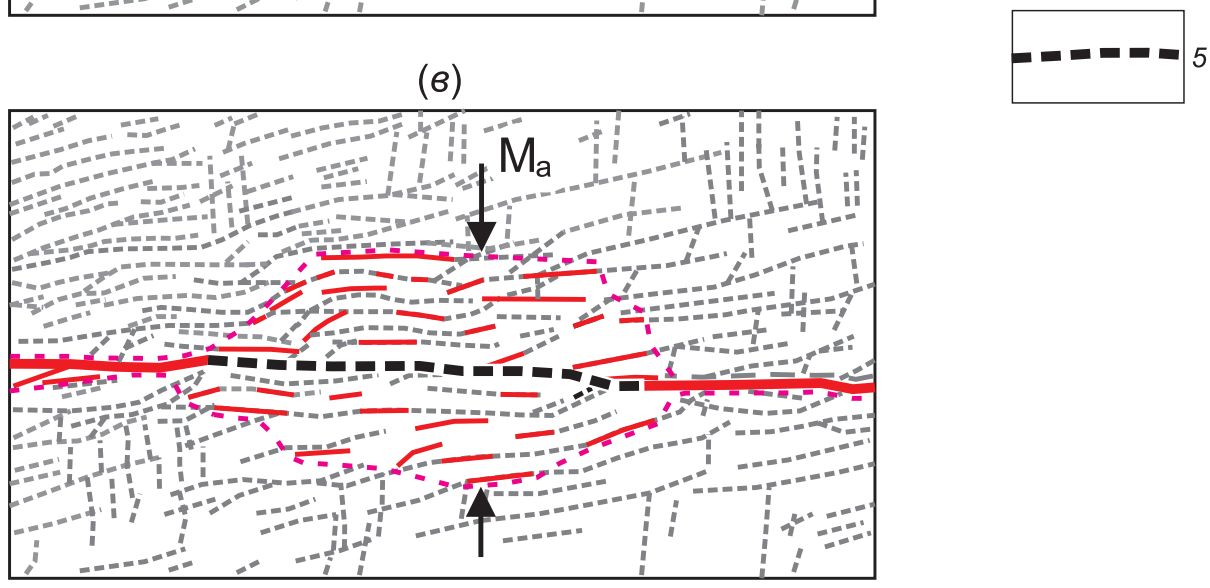

Рис. 9. Фрагмент области активного динамического влияния левостороннего сдвига в модели $(a)$ и ее структурные схемы при полной (б) и сегментной ( 8 ) активности центрального магистрального разрыва.

1 - активный магистральный разрыв; 2 - пассивные второстепенные разрывы; 3 - активные второстепенные разрывы; 4 - границы области активного динамического влияния магистрального разрыва; 5 - пассивный сегмент магистрального разрыва.

Fig. 9. Fragment of the zone of active dynamic influence of the left-lateral strike-slip fault (ZADIF) in the model (a). Structural diagrams of ZADIF: full activation of the central major fault (б), active segments of the central major fault ( $(8)$.

1 - active major fracture; 2 - passive secondary fractures; 3 - active secondary fractures; 4 - ZADIF boundary; 5 - passive segment of the major fault.

упругой оптически-активной моделях литосферы для изучения механизма, ответственного за подготовку и реализацию его периодических полных активизаций. Полученные результаты показали, что в качестве такого механизма выступает процесс сегментации с разделением разрыва по простиранию на серию перемежающихся активных и пассивных сегментов. Сегментация протекает закономерно в рамках регрессивной и прогрессивной фаз деформационного процесса с проявлением двух одноименных сценариев эволюции активных сегментов в их пределах. В первую фазу, на фоне релаксационного снижения напряжений на плоскости разрыва, смещения по нему происходят 
фрагментарно на нескольких относительно крупных сегментах, распадающихся впоследствии на серию более мелких с постепенным переходом большей их части в пассивное состояние к концу этой фазы. Во вторую фазу падение напряжений сменяется их ростом и процесс сегментации протекает в обратном направлении через объединение мелких сегментов в более крупные, заканчиваясь полной активизацией всего разрыва. С вариациями сегментной активности разрыва тесно связаны вариации напряжений в его окрестностях, где проявлены системы пластических микросдвигов. Установлено, что деформационная динамика активных сегментов на разрыве и пластических микросдвигов в его крыльях на отдельных временных интервалах существенно различается. Из этого следует важный методический вывод для статистических прогнозных оценок о необходимости дробного анализа выборок землетрясений в зонах крупных сейсмоопасных разломов. Их следует подразделять на центральную узкую подзону с магистральной плоскостью сместителя, являющуюся источником главной сеймогенерации, и две обрамляющие ее внешние широкие подзоны, с потенциально возможным проявлением в них сопутствующей сейсмичности в виде форшоков и афтершоков.

В целом, результаты экспериментов способствуют развитию представлений о геодинамике крупных разломов в сейсмических зонах литосферы и показывают один из возможных механизмов подготовки в них сильных землетрясений.

\section{7. ЛИТЕРАTУРА / REFERENCES}

Aki K., 1965. Maximum likelihood estimate of $\mathrm{b}$ in the formula $\log \mathrm{N}=\mathrm{a}-\mathrm{bM}$ and its confidence limits. Bulletin of the Earthquake Research Institute, Tokyo University 43, 237-239.

Amitrano D., 2003. Brittle-ductile transition and associated seismicity: Experimental and numerical studies and relationship with the b value. Journal of Geophysical Research: Solid Earth 108 (B1), 2044. https://doi.org/10.1029/ 2001JB000680.

Bak P., Tang C., 1989. Earthquakes as a self-organized critical phenomenon. Journal of Geophysical Research: Solid Earth 94 (B11), 15635-15637. https://doi.org/10.1029/JB094iB11p15635.

Berg E., 1968. Relation between earthquake foreshocks, stress and mainshocks. Nature 219 (5159), 1141-1143. https://doi.org/10.1038/2191141a0.

Bornyakov S.A., 1990. Quantitative analysis of parameters of shear faults varying in scale. Geologiya i Geofizika (Soviet Geology and Geophysics) 31 (10), 34-42 (in Russian) [Борняков С.A. Количественный анализ параметров разномасштабных сдвигов // Геология и геофизика. 1990. Т. 31. № 10. С. 34-42].

Bornyakov S.A., Panteleev I.A., Tarasova A.A., 2016a. Dynamics of intrafault deformation waves: results of physical simulation. Doklady Earth Sciences 47 (2), 1316-1318. https://doi.org/10.1134/S1028334X16120175.

Bornyakov S.A., Panteleev I.A., Tarasova A.A., 2016b. Discrete deformation wave dynamics in shear zones: Physical modelling results. Geodynamics \& Tectonophysics 7 (2), 289-302 (in Russian) [Борняков С.А., Пантелеев И.А., Тарасова А.А. Дискретно-волновая динамика деформаций в сдвиговой зоне: результаты физического моделирования // Геодинамика и тектонофизика. 2016. Т. 7. № 2. C. 289-302]. https://doi.org/10.5800/GT2016-7-2-0207.

Bornyakov S.A., Seminsky K.Z., Buddo V.Y., Miroshnichenko A.I., Cheremnykh A.V., Cheremnykh A.S., Tarasova A.A., 2014. Main regularities of faulting in lithosphere and their application (based on physical modeling results). Geodynamics \& Tectonophysics 5 (4), 823-861 (in Russian) [Борняков С.А., Семинский К.Ж., Буддо В.Ю., Мирошниченко А.И., Черемных А.В., Черемных А.С., Тарасова А.А. Основные закономерности разломообразования в литосфере (по результатам физического моделирования) // Геодинамика и тектонофизика. 2014. Т. 5. № 4. C. 823-861]. https://doi.org/10.5800/GT-2014-5-4-0159.

Brace W.F., Byerlee J.D., 1966. Stick-slip as a mechanism for earthquakes. Science 153 (3739), 990-992. https:// doi.org/10.1126/science.153.3739.990.

Choi J.H., Edwards P., Ko K., Kim Y.S., 2016. Definition and classification of fault damage zones: A review and a new methodological approach. Earth-Science Reviews 152, 70-87. https://doi.org/10.1016/j.earscirev.2015.11.006.

Goebel T.H., Kwiatek G., Becker T.W., Brodsky E.E., Dresen G., 2017. What allows seismic events to grow big?: Insights from b-value and fault roughness analysis in laboratory stick-slip experiments. Geology 45 (9), 815-818. https:// doi.org/10.1130/G39147.1.

Golitsyn C.S., 1996. Earthquakes from the standpoint of scaling theory. Transactions (Doklady) of the Russian Academy of Sciences, Earth Science Sections 346 (1), 166-169.

Guđmundsson A., Mohajeri N., 2013. Relations between the scaling exponents, entropies, and energies of fracture networks. Bulletin de la Société Géologique de France 184 (4-5), 373-382. https://doi.org/10.2113/gssgfbull.184. 4-5.373.

Gzovsky M.V., 1975. Fundamentals of Tectonophysics. Nauka, Moscow, 536 p. (in Russian) [Гзовский М.В. Основы тектонофизики. М.: Наука, 1975. 536 с]. 
Ma J., Guo Y., Sherman S.I., 2014. Accelerated synergism along a fault: A possible indicator for an impending major earthquake. Geodynamics \& Tectonophysics 5 (2), 387-399. https://doi.org/10.5800/GT-2014-5-2-0134.

Ma J., Sherman S.I., Guo Y.S., 2012. Identification of meta-instable stress state based on experimental study of evolution of the temperature field during stick-slip instability on a $5^{\circ}$ bending fault. Science China Earth Sciences 55 (6), 869-881. https://doi.org/10.1007/s11430-012-4423-2.

Myachkin V.I., Kostrov B.V., Sobolev G.A., Shamina O.G., 1975. Fundamentals of the physics of earthquake focus and forerunners. In: M.A. Sadovsky (Ed.), Physics of earthquake focus. Nauka, Moscow, p. 6-29 (in Russian) [Мячкин В.И., Костров Б.В., Соболев Г.А., Шамина О.Г. Основы физики очага и предвестники землетрясений // Физика очага землетрясения / Ред. М.А. Садовский. М.: Наука, 1975. С. 6-29].

Nanjo K.Z., Hirata N., Obara K., Kasahara K., 2012. Decade-scale decrease in b value prior to the M9-class 2011 Tohoku and 2004 Sumatra quakes. Geophysical Research Letters 39 (20), L20304. https://doi.org/10.1029/2012GL 052997.

Osokina D.N., 1963. Plastic and Elastic Low-Module Optically Active Materials in Studies of Crustal Stresses by the Modelling Method. The USSR Acad. Sci. Publishing House, Moscow, 196 p. (in Russian) [Осокина Д.Н. Пластичные и упругие низкомодульные оптически-активные материалы для исследования напряжений в земной коре методом моделирования. М.: Изд-во АН СССР, 1963. 196 с.].

Osokina D.N., Bondarenko P.M., 1989. Application issues of polarization optical method in experimental tectonics for modelling of tectonic stress fields. In: Experimental tectonics. Methods, results, and prospects. Nauka, Moscow, p. 78-125 (in Russian) [Осокина Д.Н., Бондаренко П.М. Вопросы применения поляризационно-оптического метода в экспериментальной тектонике для моделирования тектонических полей напряжений // Экспериментальная тектоника. Методы, результаты, перспективы. М.: Наука, 1989. С. 78-125].

Panteleev I., Plekhov O., Pankov I., Evseev A., Naimark O., Asanov V., 2014. Experimental investigation of the spatiotemporal localization of deformation and damage in sylvinite specimens under uniaxial tension. Engineering Fracture Mechanics 129, 38-44. https://doi.org/10.1016/j.engfracmech.2014.08.004.

Rivière J., Lv Z., Johnson P.A., Marone C., 2018. Evolution of $b$-value during the seismic cycle: Insights from laboratory experiments on simulated faults. Earth and Planetary Science Letters 482, 407-413. https://doi.org/10.1016/ j.epsl.2017.11.036.

Scholz C.H., 1968. The frequency-magnitude relation of microfracturing in rock and its relation to earthquakes. Bulletin of the Seismological Society of America 58 (1), 399-415.

Seminsky K.Zh., 1986. Structural and Mechanical Properties of Clayey Pastes as Model Material in Tectonic Experiments. IEC SB of the USSR Acad. Sci., Irkutsk, 130 p. VINITI 13.08.86. 5762-B86 (in Russian) [Семинский К.Ж. Структурно-механические свойства глинистых паст как модельного материала в тектонических экспериментах. Иркутск: ИЗК СО АН СССР, 1986. 130 с. ВИНИТИ 13.08.86. № 5762-В86].

Seminsky K.Zh., 2003. The Internal Structure of Continental Fault Zones. Tectonophysical Aspect. GEO Branch, Publishing House of SB RAS, Novosibirsk, 243 p. (in Russian) [Семинский К.Ж. Внутренняя структура континентальных разломных зон. Тектонофизический аспект. Новосибирск: Изд-во СО РАН, филиал «Гео», 2003. 243 с.]

Sherman S.I., 1977. Physical Regularities of Faulting in the Earth's Crust. Nauka, Siberian Branch, Novosibirsk, 102 p. (in Russian) [Шерман С.И. Физические закономерности развития разломов земной коры. Новосибирск: Наука. С0, 1977. 102 с.].

Sherman S.I., 1984. Physical experiment in tectonics and the theory of similarity. Geologiya i Geofizika (Russian Geology and Geophysics) 25 (3), 8-18 (in Russian) [Шерман С.И. Физический эксперимент в тектонике и теория подобия // Геология и геофизика. 1984. Т. 25. № 3. С. 8-18].

Sherman S.I., 2014. Seismic Process and the Forecast of Earthquakes: Tectonophysical Conception. Academic Publishing House "Geo", Novosibirsk, 359 p. (in Russian) [Шерман С.И. Сейсмический процесс и прогноз землетрясений: тектонофизическая концепция. Новосибирск: Академическое издательство «Гео», 2014. 359 c.].

Sherman S.I., Bornyakov S.A., Buddo V.Yu., 1983. Areas of Dynamic Influence of Faults (Modeling Results). Nauka, Novosibirsk, 110 p. (in Russian) [Шерман С.И., Борняков С.А., Буддо В.Ю. Области динамического влияния разломов (результаты моделирования). Новосибирск: Наука, 1983. 110 с.].

Sherman S.I., Seminsky K.Zh., Bornyakov S.A., Buddo V.Yu., Lobatskaya R.M., Adamovich A.N., Truskov V.A., Babichev A.A., 1991. Faulting in the Lithosphere. Shear Zones. Nauka, Siberian Branch, Novosibirsk, 261 p. (in Russian) [Шерман С.И., Семинский К.Ж., Борняков С.А., Буддо В.Ю., Лобацкая Р.М., Адамович А.Н., Трусков В.А., Бабичев А.А. Разломообразование в литосфере. Зоны сдвига. Новосибирск: Наука. СО, 1991. 261 с.].

Sutton M.A., Orteu J.J., Schreier H.W., 2009. Image Correlation for Shape, Motion and Deformation Measurements: Basic Concepts, Theory and Applications. Springer, New York, $322 \mathrm{p}$.

Tocher D., 1958. Earthquake energy and ground breakage. Bulletin of the Seismological Society of America 48 (2), 147-153.

Zubarev D.N., Morozov V.G., Repke G., 2002. Statistical Mechanics of Non-Equilibrium Processes. Fizmatlit, Moscow, 431 p. (in Russian) [Зубарев Д.Н., Морозов В.Г., Репке Г. Статистическая механика неравновесных процессов. М.: Физматлит, 2002. 431 с.]. 


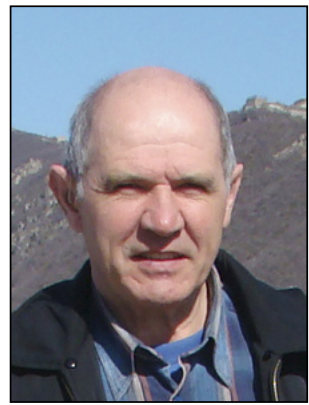

Сергей Александрович Борняков, канд. геол.-мин. наук, с.н.с.

Институт земной коры СО РАН

664033, Иркутск, ул. Лермонтова, 128, Россия

Иркутский государственный университет, геологический факультет 664003, Иркутск, ул. Ленина, 3, Россия

$\triangle$ e-mail: bornyak@crust.irk.ru

ORCID ID https://orcid.org/0000-0002-5119-1092

Sergei A. Bornyakov, Candidate of Geology and Mineralogy, Senior Researcher Institute of the Earth's Crust, Siberian Branch of RAS

128 Lermontov street, Irkutsk 664033, Russia

Irkutsk State University, Geological Faculty

3 Lenin street, Irkutsk 664003, Russia

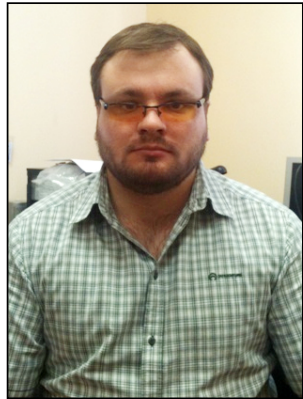

Иван Алексеевич Пантелеев, канд. физ.-мат. наук, с.н.с.

Институт механики сплошных сред УрО РАН

614013, Пермь, ул. Академика Королева, 1, Россия

e-mail: pia@icmm.ru

ORCID ID https://orcid.org/0000-0002-7430-3667

Ivan A. Panteleev, Candidate of Physics and Mathematics, Senior Researcher Institute of Continuous Media Mechanics, Ural Branch of RAS

1 Academician Korolev street, Perm 614013, Russia

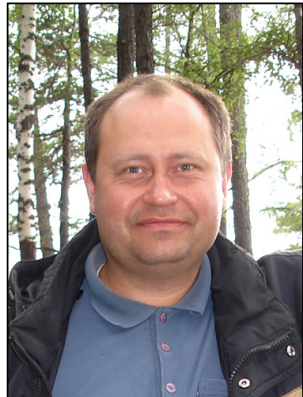

Александр Викторович Черемных, канд. геол.-мин. наук, с. н. с.

Институт земной коры СО РАН

664033, Иркутск, ул. Лермонтова, 128, Россия

e-mail: cherem@crust.irk.ru

ORCID ID https://orcid.org/0000-0001-6239-1412

Alexander V. Cheremnykh, Candidate of Geology and Mineralogy, Senior Researcher Institute of the Earth's Crust, Siberian Branch of RAS

128 Lermontov street, Irkutsk 664033, Russia

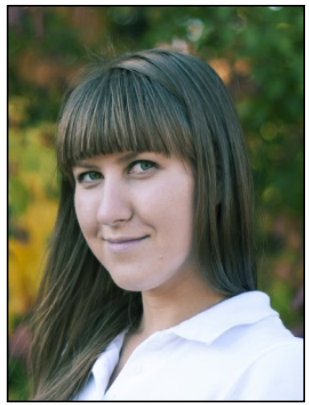

Анастасия Алексеевна Каримова, ведущий инженер

Институт земной коры СО РАН

664033, Иркутск, ул. Лермонтова, 128, Россия

Anastassia A. Karimova, Lead Engineer

Institute of the Earth's Crust, Siberian Branch of RAS

128 Lermontov street, Irkutsk 664033, Russia 